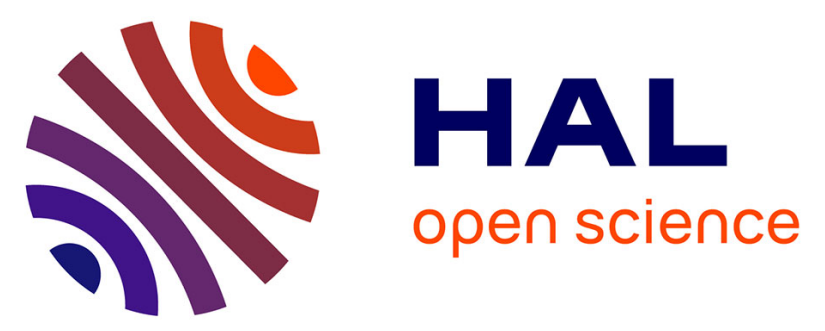

\title{
Structural-scale modeling of the active confinement effect in the steel-concrete bond for reinforced concrete structures
}

C. Turgut, Ludovic Jason, L. Davenne

\section{- To cite this version:}

C. Turgut, Ludovic Jason, L. Davenne. Structural-scale modeling of the active confinement effect in the steel-concrete bond for reinforced concrete structures. Finite Elements in Analysis and Design, 2020, 172, pp.103386. 10.1016/j.finel.2020.103386 . hal-02946623

HAL Id: hal-02946623

https://hal.science/hal-02946623

Submitted on 16 Apr 2021

HAL is a multi-disciplinary open access archive for the deposit and dissemination of scientific research documents, whether they are published or not. The documents may come from teaching and research institutions in France or abroad, or from public or private research centers.
L'archive ouverte pluridisciplinaire HAL, est destinée au dépôt et à la diffusion de documents scientifiques de niveau recherche, publiés ou non, émanant des établissements d'enseignement et de recherche français ou étrangers, des laboratoires publics ou privés. 


\title{
1 Structural-scale modeling of the active confinement effect in the steel- concrete bond for reinforced concrete structures
}

\author{
C. Turgut*, L. Jason*, L. Davenne**
}

* SEMT, CEA DEN, Université Paris Saclay, F-91191 Gif sur Yvette, France

Email:1udovic.jason@cea.fr

** LEME, UPL, Univ Paris Nanterre, F-92410 Ville d'Avray, France

\section{Abstract}

A numerical model to take into account the effect of the stress state on the bond behavior between steel and concrete in reinforced concrete structures is proposed. It is based on a zero thickness element, adapted to large-scale simulations and the use of $1 \mathrm{D}$ elements for steel bars. The proposed

\section{Introduction}

Steel is widely used in civil engineering applications to strengthen concrete in tension. These socalled reinforced concrete structures, which present a more ductile behavior compared to plain concrete, may nevertheless be subjected to cracking. In this case, when a crack initiates, stresses in concrete drop to zero and the loading is totally supported by the reinforcement. They are then responsible for stress transfer around the crack from steel to concrete. This progressive redistribution, which can be easily demonstrated in the case of a reinforced concrete tie (Figure 1) [1], is directly influenced by the bond properties [2]. That is why the influence of the steel-concrete bond has to be carefully studied, especially when the crack properties, which are directly related to this stress distribution, play a key role in the structural functions (failure mode and confinement [3] for example).

Experimentally, steel-concrete bond is generally described following three different steps [4]: a perfect "chemical" bond (no slip), then a gradual degradation of concrete around the steel ribs, followed by crack propagation (associated with a steel-concrete slip), and finally a total degradation of the interface with only a residual friction. It generally leads to the definition of an adhesion law that gives the evolution of the bond stress as a function of the slip at the interface (Figure 2). The influent parameters on this adhesion law have been widely studied in the literature. 


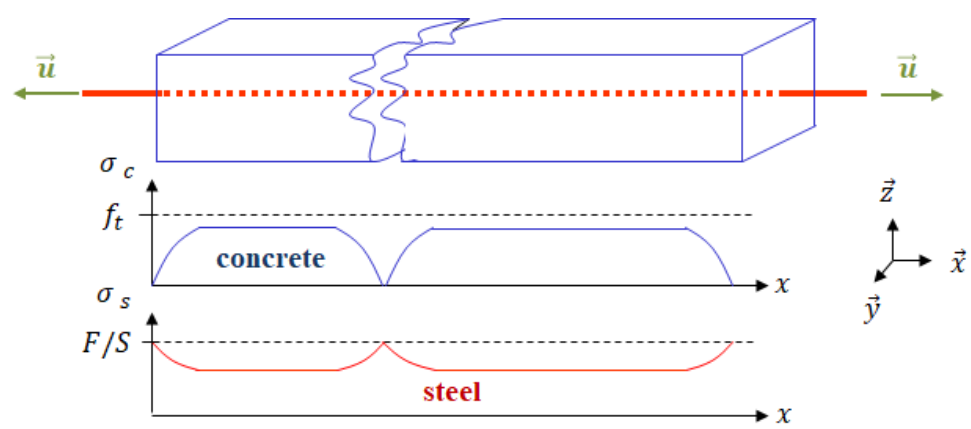

Figure 1. Principle of the distribution of steel and concrete stresses in a reinforced concrete tie after the first $\operatorname{crack}\left(\sigma_{\mathrm{c}}\right.$ and $\sigma_{\mathrm{s}}$ stand for the stresses in concrete and steel respectively) [1].

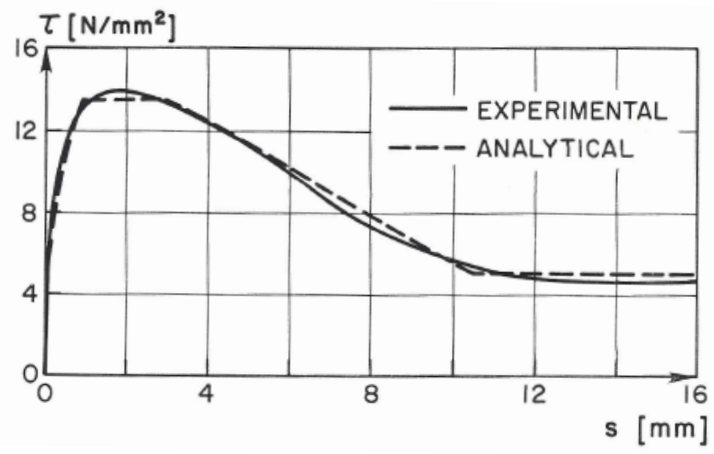

Figure 2 : Example of experimental bond stress-slip law [5].

Steel and concrete properties (relative rib area [6], steel diameter [7], concrete compressive and tensile strength [8]-[9] and concrete cover to steel diameter ratio [10]) can be considered as the main impacting parameters. They lead to potential complex formulations for the adhesion law, including a distinction between splitting and pullout failure ([11] among others).

Besides these material or geometrical parameters, the stress state around the reinforcement may have also an impact on the adhesion law. Especially, the confinement inside concrete may increase the bond strength. This confinement effect can be induced either directly (by the application of an external loading, like a pressure or a prestress) or indirectly (through the presence of secondary reinforcements which prevents concrete cracking in certain directions [12]). Experimental studies, generally performed on pullout tests, conclude on a positive influence of the concrete compression stress state, whose range is dependent on the geometry of the specimen (concrete cover) [13] [14]. Eligehausen et al. [5] especially showed that the maximum bond stress increases with the imposed lateral pressure. Malvar [15] obtained around twice the initial bond strength by applying a lateral pressure from 3.5 to $31 \mathrm{MPa}$. Verderame et al. [16] and Jin et al. [17] demonstrated that the active confinement had a significant effect on the cyclic bond behavior.

Some empirical formula were then proposed for the adhesion law to take into account this effect. Based on the experimental observations from [5], [15] and [18], Lowes et al. [19] proposed a relationship between the ultimate bond strength and the confining pressure, which explicitly includes the lateral pressure. Xu et al. [20], Zhang et al. [21], Wu et al. [22] also included the positive effect of lateral compression and the negative effect of lateral tension [23] in the bond stress - slip law.

Even if the influence of the stress state on the bond properties has been experimentally observed, its inclusion in a finite element model, compatible with engineering computations, is rather rare in the literature, despite the attempts from Lowes et al. [19] for example. In this contribution, a dedicated 
finite element model is thus proposed, based on the initial contribution from Mang et al. [24]. It is improved to take into account the stress state in the bond behavior. It supposes the definition of a bond stress - slip law, which is dependent on the stress state. A law is proposed and discussed by a comparison to experimental results on pullout tests. Finally, the simulation of a reinforced concrete tie subjected to different lateral pressures illustrates the impact of the confinement at a structural level. It is especially shown how the lateral pressure can affect the transfer length between steel and concrete.

\section{Steel concrete bond model including "confinement" effect}

\subsection{Presentation of the interface element}

When reinforced concrete structures are considered, one of the most usual hypotheses, especially for engineering computations, is to model the steel reinforcement as truss elements and to consider a no-slip perfect relation between steel and concrete. This perfect relation is generally applied through kinematic relations between both models, using the shape functions of each element. However, it may have consequences, especially when the crack properties (spacing and openings) are studied, as the steel - concrete bond directly influences their evolutions ([25] for example). To take into account the interfacial behavior between steel and concrete in a more appropriate manner, different models exist. They range from analytical or semi-analytical approaches (tension-stiffness effect in uniaxial tension [26], [27]) to more complex simulation methods (including fracture mechanics [28]). In the frame of finite element method and continuum mechanics, Ngo and Scordelis [29] proposed a spring element, associated with a linear law, to relate concrete and steel nodes. To improve the description of the bond behavior, joint elements have been developed. These zero thickness elements, introduced at the interface between steel and concrete, allow the use of a nonlinear law ([30], [31] among others). Special finite elements can also be used to enclose, in a same element, the material behavior (steel or/and concrete) and the bond effects [32]. Ibrahimbegovic et al. [33]), among others, also proposed embedded elements whose principle is to describe the steel-concrete bond behavior through an enrichment of the degrees of freedom. Even if these solutions give appropriate results, one of their main drawbacks, in the context of industrial applications, is the need to explicitly consider the interface between steel and concrete. It may impose meshing difficulties and heavy computational cost which are not compatible with large scale simulations.

To overcome these difficulties, alternative solutions exist. For example, in [34], the slippage is accounted for in an indirect manner through damage factors and the method is applied successfully to full-scale RC structures. However, when the values of the slip are needed (for example, to capture the position and the opening of the cracks [35]), the slippage has to be explicitly computed. To do so, Lykidis [36] proposed a link element using 1D rebar elements embedded within 20-noded hexahedral element. An alternative approach has also been developed in [1] then [24] to represent bond effects between steel, modeled with truss elements, and the surrounding 3D concrete through a "1D-3D" interface element. This type of developments can be seen as a macroscopic representation of local effects at the interface between steel bar ribs and surrounding concrete. It is to be noted that these local effects could be also considered at a very local scale using only adapted constitutive laws for concrete and steel. However, the resulting approach would not be compatible with structural scale computations, contrary to the proposed strategy. 
$\{\delta(\xi)\}=\left\{\delta_{t}(\xi) \quad \delta_{n_{1}}(\xi) \quad \delta_{n_{2}}(\xi)\right\}^{T}=\overline{\bar{B}}(\xi)\{u\}$

128 with

$\overline{\bar{B}}(\xi)=\left[\overline{\overline{B_{1}}}(\xi) \quad \overline{\overline{B_{2}}}(\xi)-\overline{\overline{B_{1}}}(\xi) \quad-\overline{\overline{B_{2}}}(\xi)\right]$

Figure 4. Degrees of freedom of the interface element [24]. into account the influence of the concrete stress state.

and

$\overline{\overline{B_{1}}}(\xi)=0.5(1-\xi) \overline{\overline{I_{3}}}$

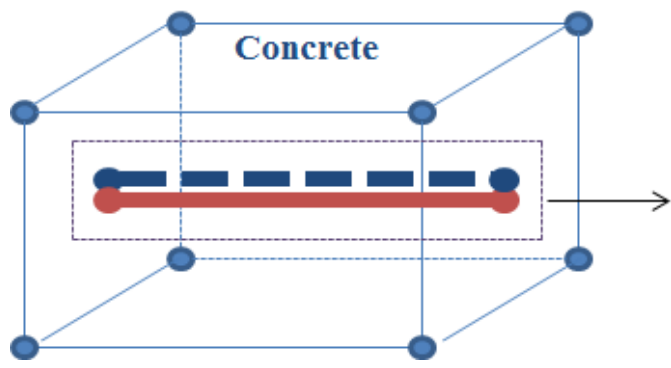

Superimposed truss element perfectly bonded to the concrete element

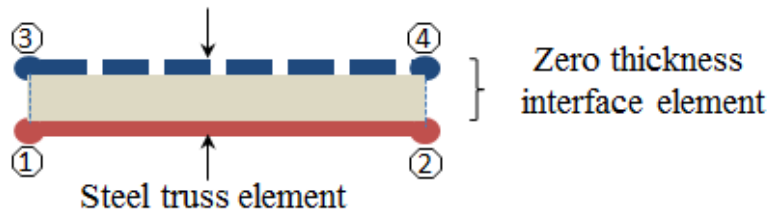

Figure 3. Principle of the interface element between steel and concrete [24].
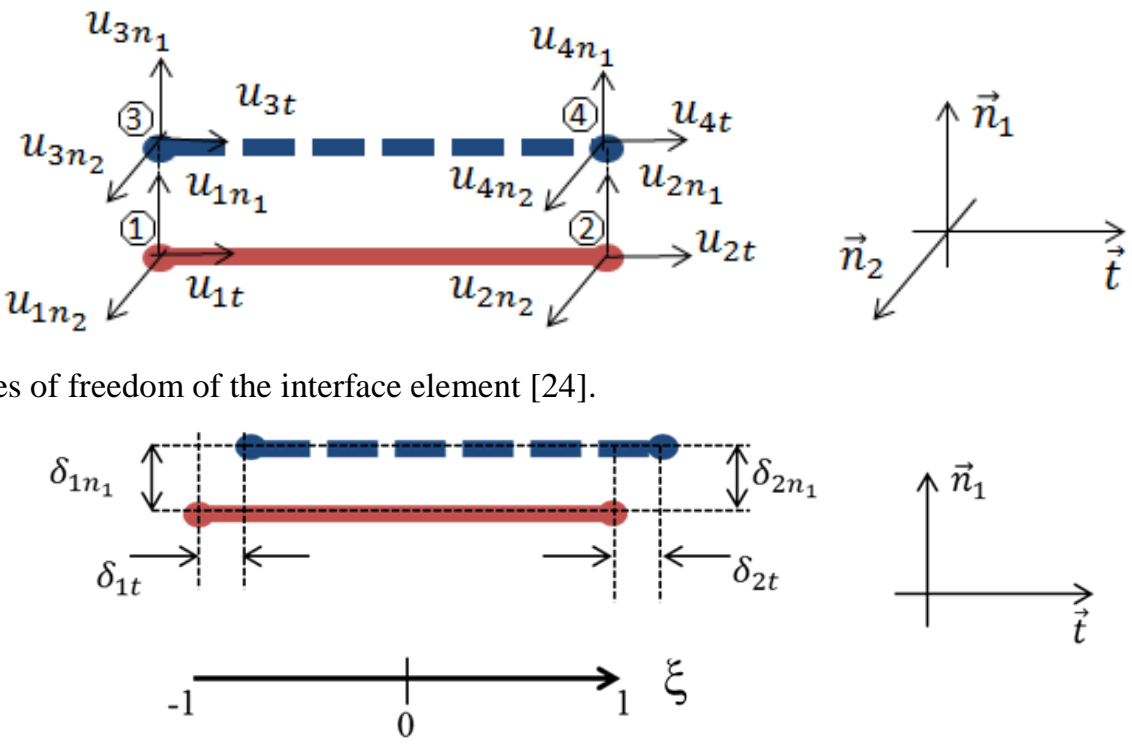

Figure 5. Definition of the slip between steel and concrete in the interface element in the $\left(\overrightarrow{\boldsymbol{t}}, \vec{n}_{1}\right)$ plane [24].

In this contribution, the formulation of the element, initially developed in [24], is improved to take

The principle of the interface element is first briefly recalled. It is a zero thickness four node element which relates each steel truss element with an associated superimposed segment, perfectly bonded to the surrounding concrete (Figure 3), through additional kinematic relations. The nodal unknowns of the reinforcement bar are thus retained and a relative slip between steel and concrete becomes possible through the interface element. Each node of the interface element has three degrees of freedom (nodal displacements) (Figure 4). The relation between the generalized slip in the local direct frame $\{\delta(\xi)\}$ (Figure 5) and the nodal displacements $\{u\}$ is written in the following form:

$\overline{\overline{B_{2}}}(\xi)=0.5(1+\xi) \overline{\overline{I_{3}}}$ 
132 where $\overline{\overline{I_{3}}}=\left[\begin{array}{lll}1 & 0 & 0 \\ 0 & 1 & 0 \\ 0 & 0 & 1\end{array}\right]$ and $-1 \leq \xi \leq 1$ (Figure 5).

133 Constitutive laws needs then to be defined between the bond stress $\{\sigma(\xi)\}=\left\{\begin{array}{c}\sigma_{t}(\xi) \\ \sigma_{n_{1}}(\xi) \\ \sigma_{n_{2}}(\xi)\end{array}\right\}$ and the slip

$134\{\delta(\xi)\}$. In the tangential direction, the tangential stress $\sigma_{t}$ is computed from the tangential slip:

$135 \sigma_{t}(\xi)=f\left(\delta_{t}(\xi)\right)$

136 In the normal directions, a linear relation is assumed between the stresses $\sigma_{\mathrm{n} 1}$ and $\sigma_{\mathrm{n} 2}$ and the 137 corresponding normal slips:

$138\left\{\begin{array}{l}\sigma_{n_{1}}(\xi) \\ \sigma_{n_{2}}(\xi)\end{array}\right\}=k_{n}\left\{\begin{array}{l}\delta_{n_{1}}(\xi) \\ \delta_{n_{2}}(\xi)\end{array}\right\}$

139 For the sake of simplicity, the value of the normal stiffness $k_{n}$ is chosen high enough to be representative of a perfect bond in the normal directions $\left(k_{n}=10^{15} \mathrm{~Pa} \cdot \mathrm{m}^{-1}\right.$ in the following). An improvement could be to take into account the effect of the slip behavior in the normal direction in a more appropriate way. One solution would be to consider a unilateral contact if normal stress is in tension, or to include a simple damage model. However, in classical configuration, the mechanical degradation of the concrete elements related to the interface element is supposed to be enough to capture the overall behavior correctly.

This first version of the model is improved to consider the effect of the confinement pressure in the tangential bond behavior. Eq. (4) is thus replaced by:

with $p_{\text {lat }}$ the concrete confinement pressure. It is computed using the same definition as in [20] [21] and based, by hypothesis, on the mean value of the normal concrete stresses:

$p_{\text {lat }}=\frac{\sigma_{n 1 n 1}+\sigma_{n 2 n 2}}{2}$

where $\sigma_{n 1 n 1}$ and $\sigma_{n 2 n 2}$ are the calculated concrete stresses in $\mathrm{n}_{1}$ and $\mathrm{n}_{2}$ directions. Eq. (6) is computed at each of the two integration points of the interface element to obtain the bond nodal forces after an analytical integration [24]. The concrete stresses are thus needed to be calculated at the position of these integration points, using the shape functions of the concrete elements.

In this contribution, the distribution of the confinement pressure $p_{\text {lat }}$ is calculated at the end of each converged loading step. It is then used at the following loading step, especially for equation (6). There is no update during each internal iterative loop. This kind of consideration may delay the response of the active confinement on the bond but can be easily compensated by using sufficiently small calculation steps. Moreover, regarding the quasi-static evolution of the studied systems and the expected loading history (confinement pressure generally applied in one-step), this simplification is considered valid.

163 The general algorithm is summarized in Figure 6. The overall convergence is obtained with a tolerance equal to $10^{-4}$. 


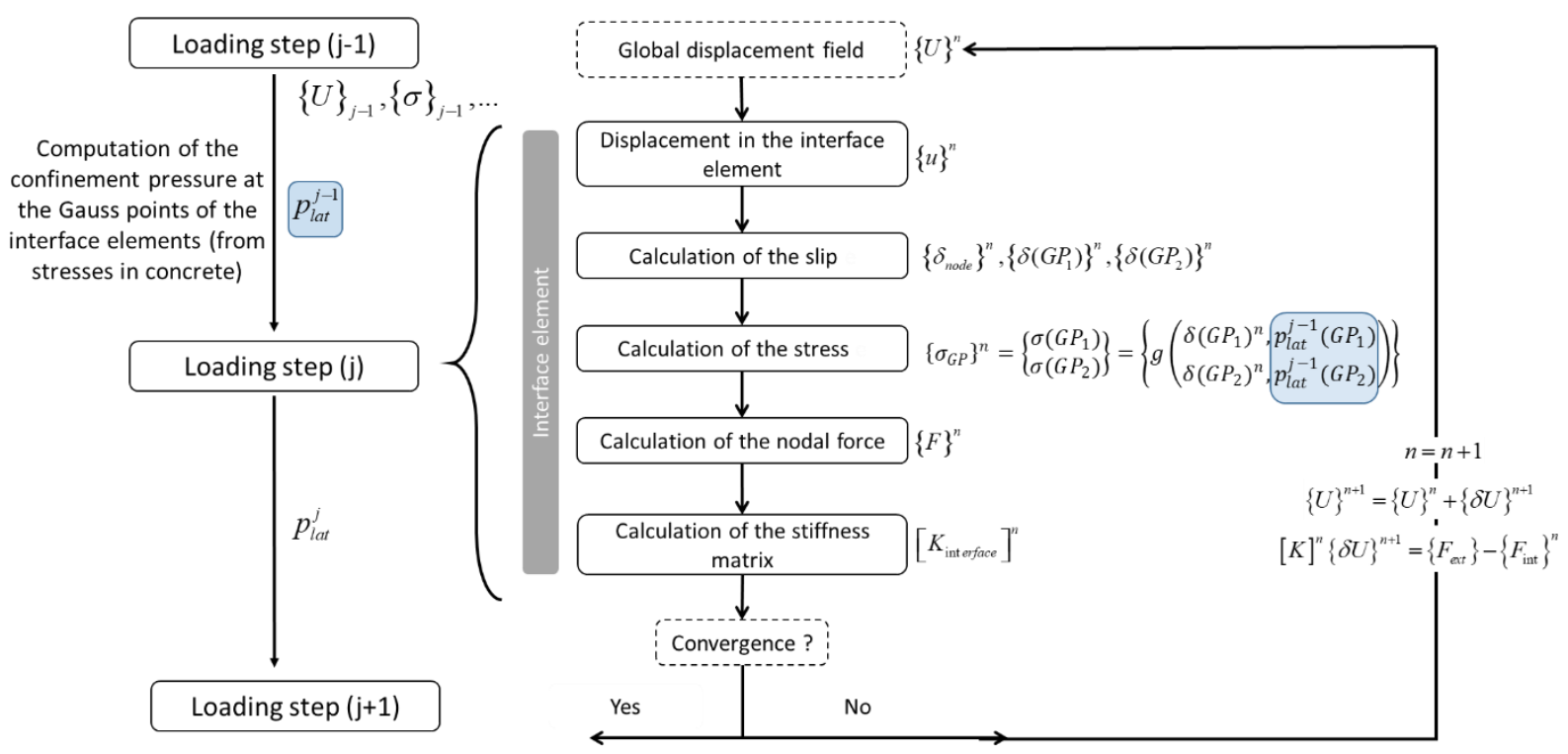

Figure 6. Principle of the resolution for the interface element. $\mathrm{j}$ stands for the loading step, $\mathrm{n}$ for the iteration number. $\mathrm{U}$ and $\mathrm{u}$ are the global displacement field and the displacement in the interface element respectively. $\delta \mathrm{U}$ is the increment in the displacement for each iteration. $\delta$ is the slip, $\sigma$ the stress and $\mathrm{GP}_{1}$ and $\mathrm{GP}_{2}$ are the positions of the two integration points for each interface element. $\mathrm{F}$ are the nodal forces and $\mathrm{K}$ the resolution matrix.

173 It is to be noted that one advantage of the proposed method is the possibility to mesh 1D steel bars and 3D concrete volumes can be meshed independently. For large industrial structures with a high number of rebars ([37] for example), an efficient mesh generation method can also be considered ([38]).

\subsection{Proposition of a tangential bond law including confinement}

As previously mentioned, taking into account the influence of the concrete stresses on the bond properties supposes the definition of an appropriate bond stress - slip law in the tangential direction. This should observe the following experimental statements:

- Zhang, et al. [14], Lowes, et al. [19], Robins and Standish [39], among others, reported that the active confinement effect is not significant on the shape of the bond law but can be considered only on the value of the bond stress for a given slip.

- Tension and compression stress states have different effects on the bond behavior. The bond strength increases with increasing lateral compression ([20], [39]), while it decreases with increasing lateral tension [22].

- Bond properties increase with the ratio of lateral pressure over the compressive strength $f_{c}$ : $\sigma_{t}=f\left(\frac{p_{\text {lat }}}{f_{c}}\right)([5],[21],[40])$

- Finally, the lower the concrete cover $c$ to steel diameter $d_{s}$ ratio, the greater the effect of lateral pressure ([20], [41]). This transition in the behavior is recognized in [42]. The confining 
pressure is considered to be only able to enhance splitting behavior (small $c / d_{s}$ ratio) whereas the pullout limit state (where the concrete fails in shear - higher $c / d_{s}$ ratio) is not enhanced significantly by confinement. This ratio has already been highlighted in case of no "active" confinement $\left(p_{\text {lat }}=0\right)$ [11].

Based on these four main considerations, the influence of the lateral pressure is proposed to be considered in Eq. (6) through Eq. (8). For sake of simplicity, in the following, $\tau$ will stand for the tangential bond stress $\sigma_{\mathrm{t}}$.

$$
\tau\left(p_{\text {lat }}, \delta_{t}\right)=\tau_{0}\left(\delta_{t}\right)\left(1-\operatorname{sgn}\left(p_{\text {lat }}\right) \cdot \alpha \sqrt{\left|\frac{p_{\text {lat }}}{f_{c}}\right|}\right)
$$

$\tau_{0}$ is the bond stress - slip law for $p_{\text {lat }}=0$ and $\alpha$ is a parameter. sgn stands for the sign of $p_{\text {lat }}(>0$ in tension and $<0$ in compression) in order to represent the different effect of the confinement in tension and in compression. $\alpha$ is defined as a function on the concrete cover to steel bar diameter ratio. A transition value for $c / d_{s}$ is especially considered, below which the influence of lateral pressure is quite strong and above which its influence is weak [20] [42]. This transition value is chosen from [11]:

$$
\left(\frac{c}{d_{s}}\right)_{t r}=0.39 \frac{f_{c}}{f_{t}}-0.24
$$

with $f_{t}$ the concrete tensile strength.

$\alpha$ is near 1 for very small $c / d_{s}$ ratios and tends toward 0 for large values, with a quite strong drop around the transition value. A continuous expression is proposed based on exponentials:

$$
\alpha=1-e^{\beta\left(\frac{c}{d}-a\right)} \text { if } \frac{c}{d_{s}}<\left(\frac{c}{d_{s}}\right)_{t r}
$$

$$
\alpha=e^{-\gamma\left(\frac{c}{d_{s}}-b\right)} \quad \text { if } \frac{c}{d_{s}}>\left(\frac{c}{d_{s}}\right)_{t r}
$$

$\beta$ and $\gamma$ are parameters to control the shape of the exponentials, while $a$ and $b$ are adjusted to assure the continuity of $\alpha$ and its derivative at the transition point $\left(\frac{c}{d_{s}}\right)_{t r}$. In the following $\beta=1$ and $\gamma=0.8$. An example of the evolution of $\alpha$ as a function of $\left(\frac{c}{d_{s}}\right)$ for $\left(\frac{c}{d_{s}}\right)_{t r}=4.5 \quad(\mathrm{a}=5.31$ and $\mathrm{b}=3.77)$ is given in Figure 7. The resulting bond stress - slip laws for $\left(\frac{c}{d_{s}}\right)=2$ and $\left(\frac{c}{d_{s}}\right)=7$ and different plat values are given in Figure 8 ( $f_{c}$ chosen equal to $\left.30 \mathrm{MPa}\right)$. In Figure 8 , a piecewise linear curve has been considered as input data for $\tau_{0}(g)$ but some more complex evolutions could also have been chosen (nonlinear curve for example). 


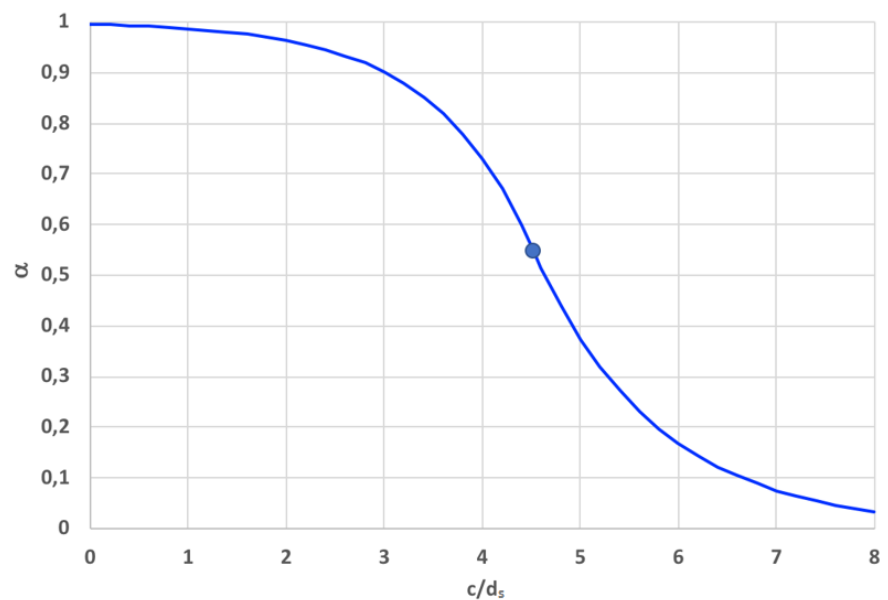

Figure 7. Evolution of $\alpha$ as a function of $c / d_{s}$ for $\left(c / d_{s}\right)_{t r}=4.5$.
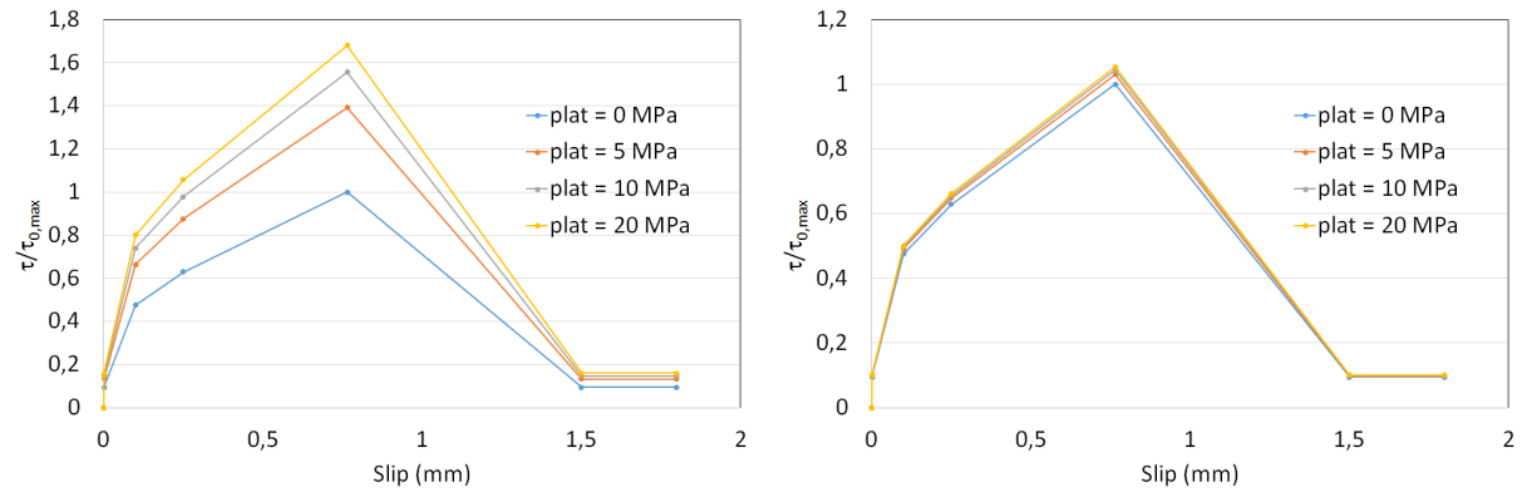

221

222

223

224

Figure 8. Bond stress - slip laws for $\left(\mathrm{c} / \mathrm{d}_{\mathrm{s}}\right)_{\mathrm{tr}}=4.5$ and $\mathrm{f}_{\mathrm{c}}=30 \mathrm{MPa}$ and different confinement pressures. Left, $\left(\mathrm{c} / \mathrm{d}_{\mathrm{s}}=2\right)$, right $\left(\mathrm{c} / \mathrm{d}_{\mathrm{s}}\right)=7 . \tau_{0, \max }$ stands for the bond strength at $\mathrm{p}_{\text {lat }}=0$.

The calibration of the bond stress - slip law can be summarized in four main steps:

- Definition of the initial interface law $\tau_{0}\left(\delta_{t}\right)$ from either experimental or empirical evolutions. In particular, the experimental bond stress - slip law obtained from a pullout test without any confining pressure $\left(\mathrm{P}_{\text {conf }}=0 \mathrm{MPa}\right)$ can be used [43]. $\tau_{0}\left(\delta_{t}\right)$ may be slightly different from the experimental pullout curve at $\mathrm{P}_{\text {conf }}=0 \mathrm{MPa}$, to take into account the effect of lateral pressure $\mathrm{p}_{\text {lat }}(\neq 0)$ around the steel bar during the pullout, even for a zero applied confinement pressure (structural stress related to the type of test). If the experimental bond stress - slip law at $P_{\text {conf }}=0 \mathrm{MPa}$ is not available, it is possible to build the expected curve using the methodology proposed in [11], solely from the material and geometric parameters.

- Given the geometrical and material parameters $\left(\frac{c}{d_{s}}\right), \mathrm{f}_{\mathrm{c}}$ and $\mathrm{f}_{\mathrm{t}}$, calculation of $\left(\frac{c}{d_{s}}\right)_{t r}$ from Eq. (9)

- Given $\left(\frac{c}{d_{s}}\right)_{t r}$, calculation of parameters a and $\mathrm{b}$ to ensure the continuity of Eq. (10) and Eq. (11) and its derivatives. Definition of $\alpha\left(\frac{c}{d_{s}}\right)$.

- Given $\alpha\left(\frac{c}{d_{s}}\right),\left(\frac{c}{d_{s}}\right)$ and $\tau_{0}\left(\delta_{t}\right)$, definition of the bond stress - slip law $\tau\left(p_{\text {lat }}, \delta_{t}\right)$ from Eq. (7) and Eq. (8). 
As a summary, for a given geometry (associated to a given $\left(\frac{c}{d_{s}}\right)$ ), and a given concrete (associated to a compressive strength and a tensile strength), the definition of the adhesion law only requires the initial bond stress - slip law $\tau_{0}\left(\delta_{t}\right)$ (for $p_{\text {lat }}=0$ ) that can be obtained either experimentally by inverse analysis or numerically (Figure 9 ).

Compared to other evolution laws that are found in literature, the proposed methodology can be viewed as more general. For example, in [44], two evolution laws were proposed for two steel diameters, without any generalization. In [20], [21], [22], the shape and the parameters of the laws were functions of the loading (compression, tension, tension - compression respectively). Moreover, these former approaches were not expected to distinguish splitting and pullout failures as it is the case for the present methodology through the comparison to the transition value of $\left(\frac{c}{d_{s}}\right)$. It can also be considered as easy to use, especially compared to more complex approaches in literature. For example, in [18], relations between the bond strength, the radial stress, the slip and the crack opening have been proposed, whose extension to a single independent relationship between concrete confinement and peak bond strength and radial force is not trivial [45]. Finally, as the proposed relation is function of the mean normal stresses around the bar, it is expected to reproduce both "active" and indirect confinements (through an applied pressure or transverse reinforcements respectively). Finally, the application to cyclic loadings could be considered, provided an adaptation of the bond stress-slip to alternative load (from [5] for example, combined with additional experimental data) and an adapted constitutive law for concrete.


Figure 9. Summary of the calibration of the bond stress - slip law, including the effect of the stress state. 


\section{Validation of the evolution law on pullout tests}

263 To validate the proposed bond stress - slip law, pullout tests from [11], [13] and [41] are simulated.

\subsection{Test specimen}

The generic geometry of pullout tests is presented in Figure 10. The detailed geometry, properties (concrete compressive strength $f_{c}$, tensile strength $f_{t}$ and Young modulus $E_{c}$, steel Young modulus $E_{s}$ and yielding stress $f_{e}$ ) and loadings (applied uniaxial or biaxial compressive confinement pressure $\left.P_{\text {conf }}\right)$ are given in Table 1 and Table 2. Concrete properties are either obtained from the given average values of experimental uniaxial compressive and tensile tests when available or evaluated using the equations provided in [2] $\left.\left(E_{c}=22000\left(\frac{f_{c}}{10}\right)^{0.3}\right), f_{t}=0.3\left(f_{c}\right)^{2 / 3}\right)$.

The proposed validation includes different concrete properties, steel diameters and confining pressures to represent a wide enough range of configurations. In particular, it encloses configurations in which the ratio of the concrete cover over the steel diameter is higher and smaller than the transition value (Eq. (9)). It means that pullout and splitting failures are both considered in the validation process.
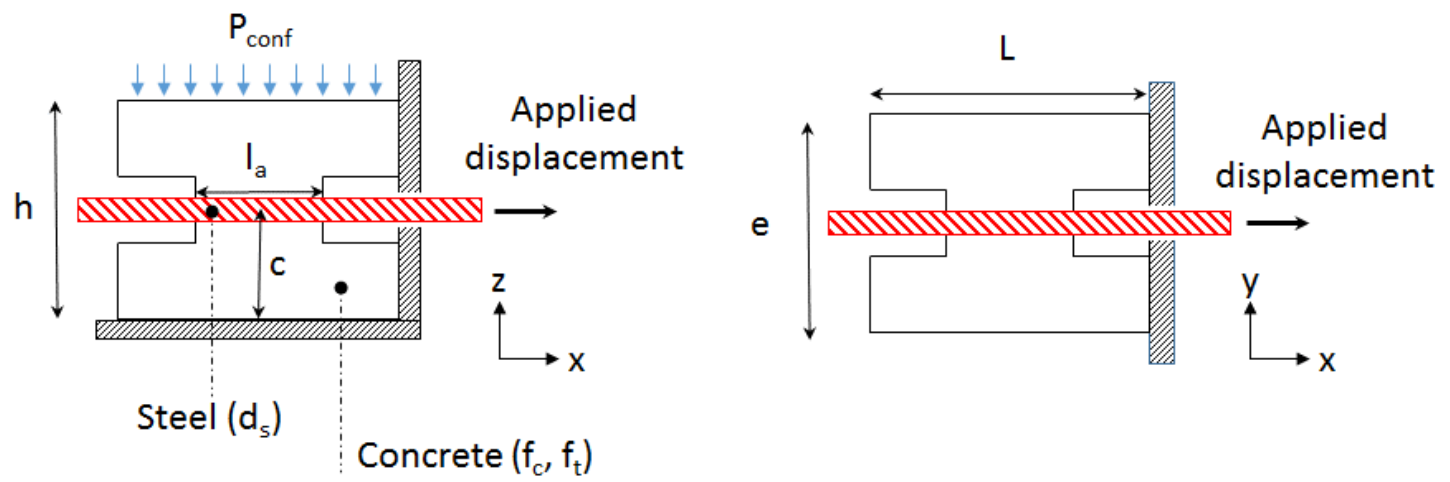

Figure 10. General geometry of pull-out tests.

\begin{tabular}{|c|c|c|c|c|c|c|}
\hline Reference of the simulated pull-out tests & $\begin{array}{c}d_{s} \\
(m m)\end{array}$ & $\begin{array}{c}\mathrm{L} \\
(\mathrm{mm})\end{array}$ & $\begin{array}{c}\mathrm{h} \\
(\mathrm{mm})\end{array}$ & $\begin{array}{c}\mathrm{e} \\
(\mathrm{mm})\end{array}$ & $\begin{array}{c}\mathrm{l}_{\mathrm{a}} \\
(\mathrm{mm})\end{array}$ & $\mathrm{c} / \mathrm{d}_{\mathrm{s}}$ \\
\hline \multirow{2}{*}{ (Xu et al., 2012) [13] } & 16 & \multirow{2}{*}{150} & \multirow{2}{*}{150} & \multirow{2}{*}{150} & \multirow{2}{*}{$5 d_{s}$} & 4.19 \\
\hline & 22 & & & & & 2.91 \\
\hline \multirow{3}{*}{ (Shang et al., 2017)[41] } & 14 & \multirow{3}{*}{150} & \multirow{3}{*}{150} & \multirow{3}{*}{150} & \multirow{3}{*}{$5 d_{s}$} & 4.86 \\
\hline & 18 & & & & & 3.67 \\
\hline & 22 & & & & & 2.91 \\
\hline (Torre-Casanova et al., 2013)[11] & 12 & 180 & 180 & 180 & 60 & 7 \\
\hline
\end{tabular}

Table 1. Geometries of simulated pullout tests. 


\begin{tabular}{|c|c|c|c|c|c|c|c|c|}
\hline \multirow{2}{*}{$\begin{array}{l}\text { Reference of the } \\
\text { simulated pull-out } \\
\text { tests }\end{array}$} & \multirow{2}{*}{$\begin{array}{c}\mathrm{d}_{\mathrm{s}} \\
(\mathrm{mm})\end{array}$} & \multirow{2}{*}{$\begin{array}{c}E_{s} \\
(\mathrm{GPa})\end{array}$} & \multirow{2}{*}{$\begin{array}{c}\mathrm{f}_{\mathrm{e}} \\
(\mathrm{MPa})\end{array}$} & \multirow{2}{*}{$\begin{array}{c}f_{c} \\
(\mathrm{MPa})\end{array}$} & \multirow{2}{*}{$\begin{array}{c}E_{c} \\
(\mathrm{GPa})\end{array}$} & \multirow{2}{*}{$\begin{array}{c}\mathrm{f}_{\mathrm{t}} \\
(\mathrm{MPa})\end{array}$} & \multicolumn{2}{|c|}{$P_{\text {conf }}$} \\
\hline & & & & & & & Type & Value (MPa) \\
\hline \multirow{2}{*}{ (Xu et al., 2012) [13] } & 16 & \multirow{2}{*}{200} & \multirow{2}{*}{400} & 35 & \multirow{2}{*}{31.7} & 3.21 & \multirow{2}{*}{ uniaxial } & \multirow{2}{*}{$0 \rightarrow 18$} \\
\hline & 22 & & & 30.25 & & 2.91 & & \\
\hline \multirow{3}{*}{$\begin{array}{c}\text { (Shang et al., 2017) } \\
{[41]}\end{array}$} & 14 & \multirow{3}{*}{200} & \multirow{3}{*}{560} & \multirow{3}{*}{33.93} & \multirow{3}{*}{31.7} & \multirow{3}{*}{3.14} & \multirow{3}{*}{ uniaxial } & \multirow{3}{*}{$0 \rightarrow 20$} \\
\hline & 18 & & & & & & & \\
\hline & 22 & & & & & & & \\
\hline $\begin{array}{l}\text { (Torre-Casanova et } \\
\text { al., 2013) [11] }\end{array}$ & 12 & 200 & 400 & 36.6 & 28 & 3.12 & biaxial & $0 \rightarrow 10$ \\
\hline
\end{tabular}

Table 2. Material properties and loadings for the pullout tests.
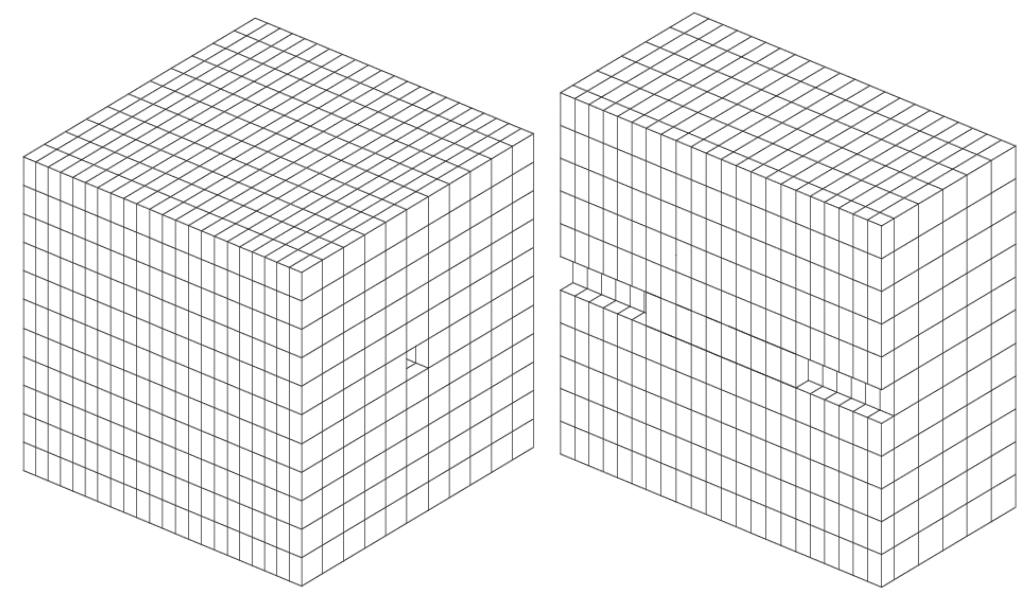

Figure 11. Example of concrete mesh for the simulations of pullout tests from [41] $-\mathrm{d}_{\mathrm{s}}=14 \mathrm{~mm}$. On the left, entire mesh, on the right, cross section along the position of the steel bar.
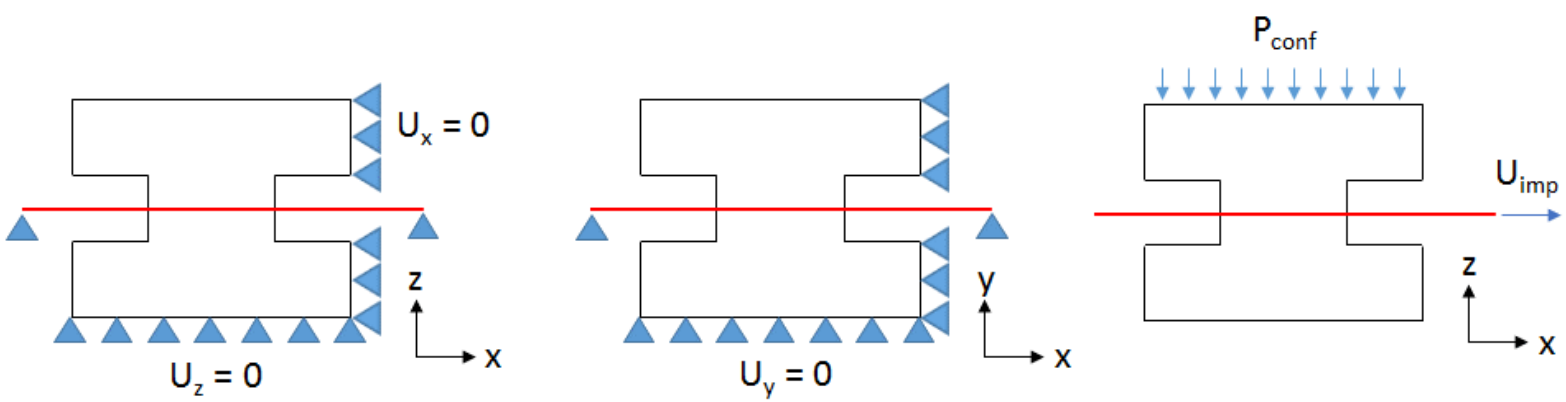

Figure 12. Boundary conditions (left and middle) and loadings (right) for the simulation of pullout tests - case of uniaxial confinement.

\subsection{Presentation of the simulations}

The simulations are performed in the finite element code Cast3M [46] using cubic elements for concrete, 1D truss elements for steel and the steel-concrete bond model presented in section 2.1. An illustration of the concrete mesh is proposed in Figure 11. The loading and boundary conditions are illustrated in Figure 12. They include zero displacement conditions on appropriate faces and imposed displacements at the loaded end of the steel bar. The confinement is modeled through a uniform 
pressure applied in one-step on the adequate face(s) at the beginning of the loading (before the imposed displacement).

Concrete behavior is simulated using a damage model, which includes irreversible strains [47]. Damage is represented by two independent variables $d^{+}$and $d^{-}$which have respectively an influence in tension and compression. The stress $\sigma$ is evaluated from the following relation:

$\boldsymbol{\sigma}=\left[1-d^{+}\left(\boldsymbol{\sigma}^{\prime+}\right)\right] \boldsymbol{\sigma}^{++}+\left[1-d^{-}\left(\boldsymbol{\sigma}^{\prime}\right)\right] \boldsymbol{\sigma}^{\prime-}$

where $\sigma^{\prime+}$ and $\sigma^{\prime-}$ correspond respectively to the positive and the negative parts of the effective stress $\sigma^{\prime}$ :

$\sigma^{\prime}=C\left(\varepsilon-\varepsilon^{p}\right)$

In this relation, $\boldsymbol{C}$ is the tensor of elasticity and $\varepsilon$ represents the total strain. $\boldsymbol{\varepsilon}^{\boldsymbol{p}}$ stands for the irreversible strains which are governed by the damage evolution in compression:

$\dot{\boldsymbol{\varepsilon}}^{p}=\beta_{p} E_{c} H\left(\dot{d}^{-}\right)\left\langle\boldsymbol{\sigma}^{\prime}: \dot{\boldsymbol{\varepsilon}}\right\rangle /\left(\boldsymbol{\sigma}^{\prime}: \boldsymbol{\sigma}^{\prime}\right) \boldsymbol{C}^{-1}: \boldsymbol{\sigma}^{\prime}$

where $\beta_{p}$ is a model parameter and $H$ is the Heaviside function. $\langle$.$\rangle represents the positive part of the$ tensor. The tensile part of the model is regularized using the Hillerborg concept of fracture energy that guarantees a constant energy release, independently from the mesh size [48]. The model parameters are chosen to be as representative as possible to the experimental uniaxial concrete properties.

For sake of simplicity, the 1D steel bar follows an elastic- perfect plastic law using the steel properties provided in Table 2. It was checked that the yielding stress was not reached during the simulation (no influence of the plastic part of the model).

The bond stress - slip law is calibrated following the methodology described in Figure 9 from the experimental result at a zero confinement pressure. The obtained simulated $p_{\text {lat }}$ distribution along the bar is given in Figure 13 at $\mathrm{P}_{\text {conf }}=0 \mathrm{MPa}$. The difference between the input law and the simulated bond behavior, which results from the inverse analysis and the effect of the non-zero plat distribution, is illustrated in Figure 14.

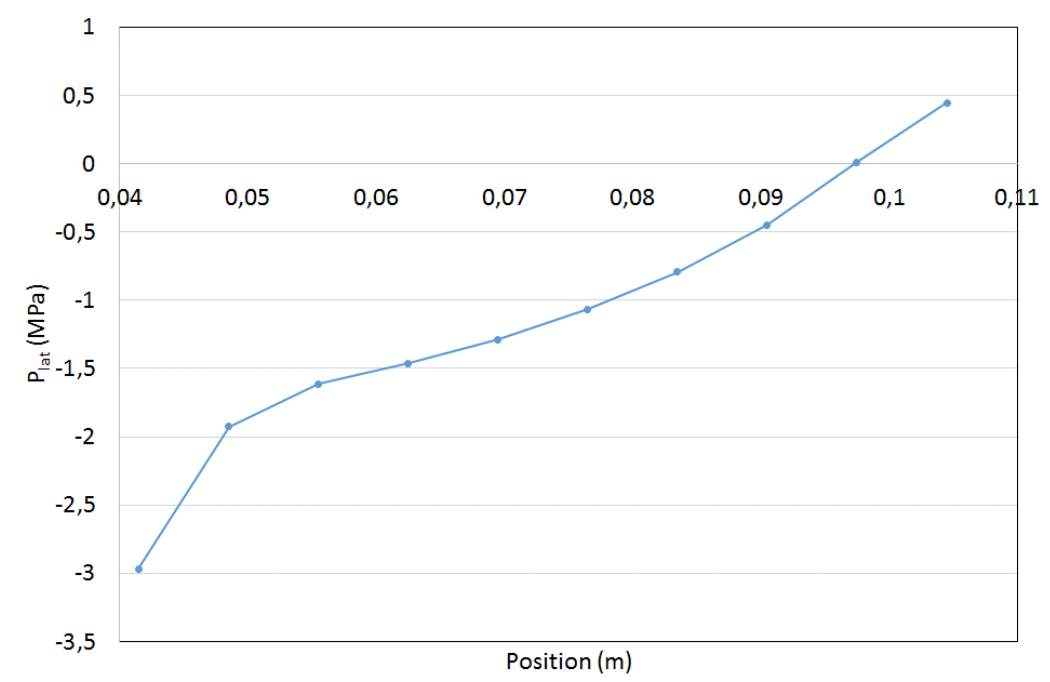

Figure 13. Simulation of a pullout test from [36] $-\mathrm{d}_{\mathrm{s}}=14 \mathrm{~mm}$. plat distribution along the steel bar for $\mathrm{P}_{\text {conf }}=0$ $\mathrm{MPa}$ at the applied displacement corresponding to the bond strength. 


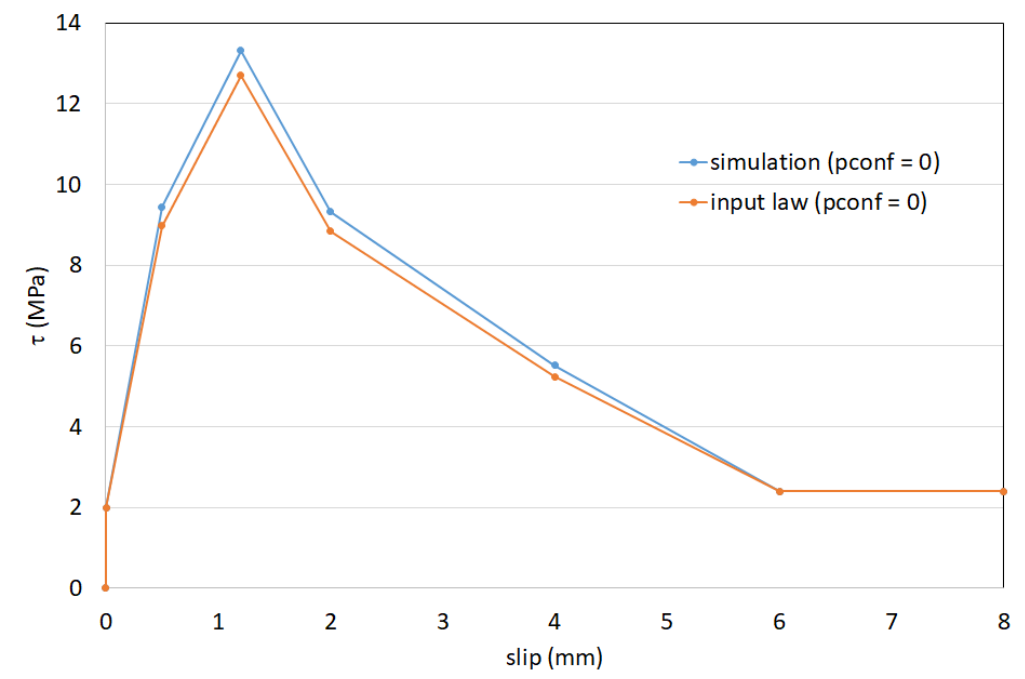

323 Figure 14. Simulation of a pullout test from [41] $-\mathrm{d}_{\mathrm{s}}=14 \mathrm{~mm}$. Input calibrated bond law and simulated bond 324 stress - slip law for $\mathrm{P}_{\text {conf }}=0 \mathrm{MPa}$.

\subsection{Results}

326 The simulated maximum bond stresses are compared to the experimental ones for different levels of 327 applied confinement pressures in Figure 15 ([41]), Figure 16 ([13]) and Figure 17 ([11]). It has been 328 chosen to perform the comparison on the bond strength, as it is the main mean characteristic, which 329 is experimentally studied. Moreover, the existence of mean values (which may be the only quantity 330 given in the experimental results - [36] for example) enable to reduce the experimental discrepancy 331 associated to this type of tests, compared to single bond stress - slip curves.

332 The simulated bond strength is calculated using the same equation as for the experiment:

$333 \tau_{\text {max }}=\frac{F_{\text {max }}}{\pi d_{s} l_{a}}$

334 where $F_{\max }$ is the maximum applied force at the loaded end of the steel bar. Eq. (15) thus represents 335 a "mean" measure of the bond along the steel bar. 

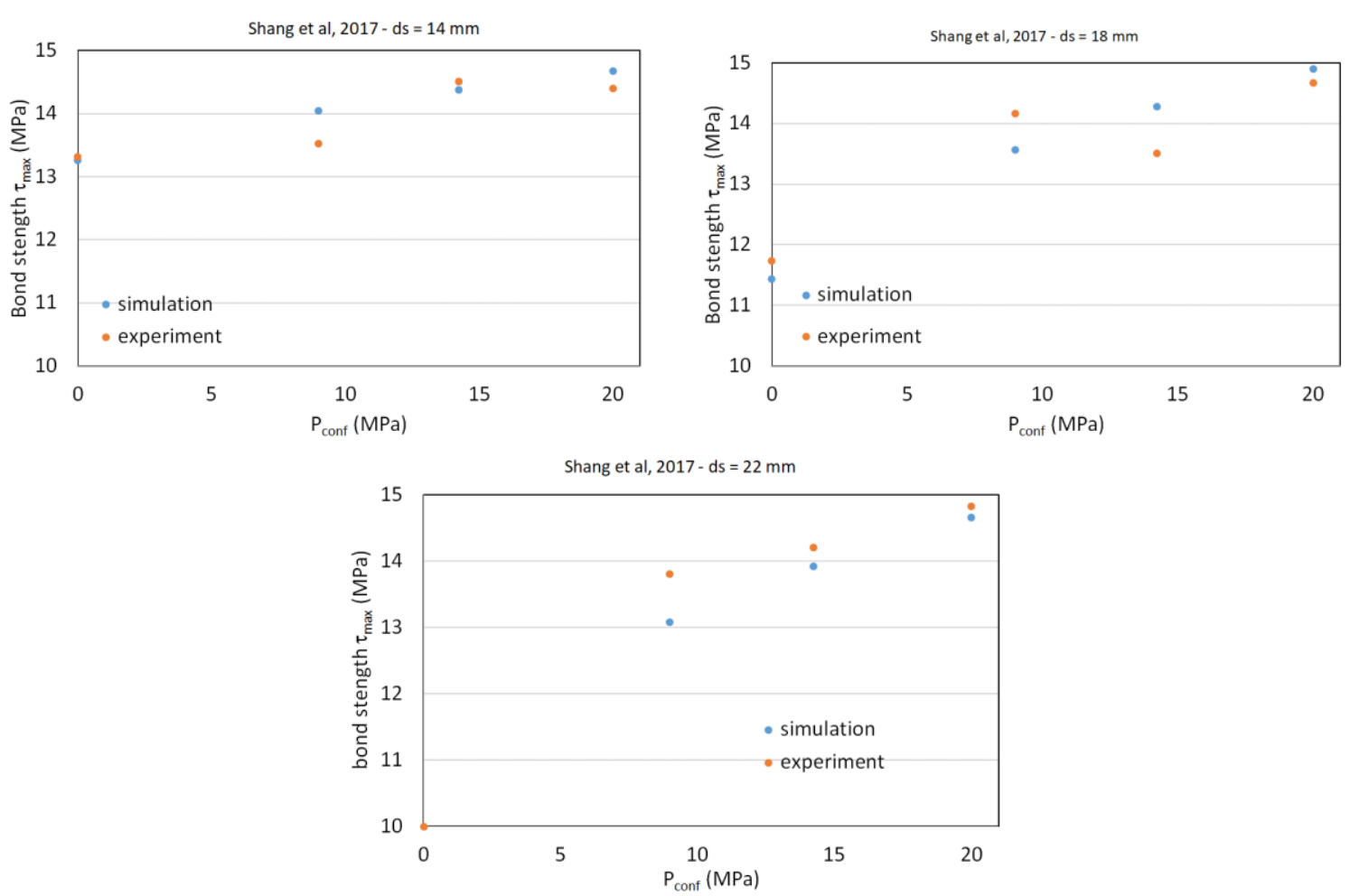

Figure 15. Evolution of the bond strength as a function of the applied confinement pressure - experiments from [41] (only mean values were experimentally provided).
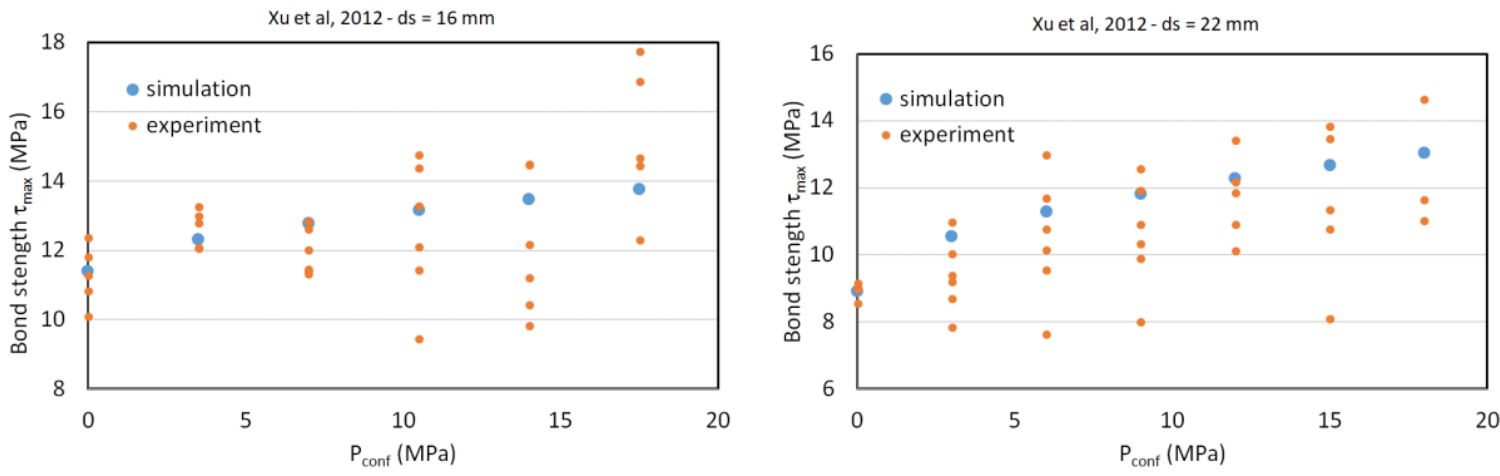

Figure 16. Evolution of the bond strength as a function of the applied confinement pressure - experiments from [13].



Figure 17. Evolution of the bond strength as a function of the applied confinement pressure - experiments from [11]. 


\begin{tabular}{|c|c|c|c|c|c|c|}
\cline { 2 - 7 } \multicolumn{1}{c|}{} & \multicolumn{3}{|c|}{$\mathrm{d}_{\mathrm{s}}=16 \mathrm{~mm}$} & \multicolumn{3}{c|}{$\mathrm{d}_{\mathrm{s}}=22 \mathrm{~mm}$} \\
\hline $\begin{array}{c}\text { Applied } \\
\text { confining } \\
\text { pressure } \\
(\mathrm{MPa})\end{array}$ & $\begin{array}{c}\text { Simulated } \\
\text { bond strength } \\
(\mathrm{MPa})\end{array}$ & $\begin{array}{c}\text { Mean } \\
\text { experimental } \\
\text { bond strength } \\
(\mathrm{MPa})\end{array}$ & $\begin{array}{c}\text { Mean error } \\
(\%)\end{array}$ & $\begin{array}{c}\text { Simulated } \\
\text { bond strength } \\
(\mathrm{MPa})\end{array}$ & $\begin{array}{c}\text { Mean } \\
\text { experimental } \\
\text { bond strength } \\
(\mathrm{MPa})\end{array}$ & $\begin{array}{c}\text { Mean error } \\
(\%)\end{array}$ \\
\hline 0 & 11.39 & 11.28 & 5.9 & 8.92 & 8.92 & 2.1 \\
\hline $0.1 \mathrm{f}_{\mathrm{c}}$ & 12.31 & 12.64 & 4.2 & 10.55 & 9.36 & 12.6 \\
\hline $0.2 \mathrm{f}_{\mathrm{c}}$ & 12.78 & 11.93 & 6 & 11.29 & 10.45 & 13.5 \\
\hline $0.3 \mathrm{f}_{\mathrm{c}}$ & 13.17 & 12.57 & 11.9 & 11.81 & 10.60 & 12.6 \\
\hline $0.4 \mathrm{f}_{\mathrm{c}}$ & 13.48 & 12.09 & 16.7 & 12.28 & 11.69 & 8.4 \\
\hline $0.5 \mathrm{f}_{\mathrm{c}}$ & 13.76 & 15.20 & 14.7 & 12.68 & 11.5 & 15.3 \\
\hline $0.6 \mathrm{f}_{\mathrm{c}}$ & - & - & - & 13.04 & 12.44 & 12.7 \\
\hline
\end{tabular}

Table 3. Simulated and experimental bond strength and mean error. Pullout tests from [13].

\begin{tabular}{|c|c|c|c|}
\cline { 2 - 4 } \multicolumn{1}{c|}{} & \multicolumn{3}{|c|}{$\mathrm{d}_{\mathrm{s}}=12 \mathrm{~mm}$} \\
$\begin{array}{c}\text { Applied } \\
\text { confining } \\
\text { pressure } \\
(\mathrm{MPa})\end{array}$ & $\begin{array}{c}\text { Simulated } \\
\text { bond strength } \\
(\mathrm{MPa})\end{array}$ & $\begin{array}{c}\text { Mean } \\
\text { experimental } \\
\text { bond strength } \\
(\mathrm{MPa})\end{array}$ & $\begin{array}{c}\text { Mean error } \\
(\%)\end{array}$ \\
\hline 0 & 24.36 & 24.27 & 9.3 \\
\hline 5 & 24.42 & 25.5 & 4.4 \\
\hline 10 & 24.54 & 26.30 & 15.1 \\
\hline
\end{tabular}

Table 4. Simulated and experimental bond strength and mean error. Pullout tests from [11].

\begin{tabular}{|c|c|c|c|c|c|c|}
\hline & \multicolumn{3}{|c|}{$\mathrm{d}_{\mathrm{s}}=14 \mathrm{~mm}$} & \multicolumn{3}{|c|}{$\mathrm{d}_{\mathrm{s}}=18 \mathrm{~mm}$} \\
\hline $\begin{array}{l}\text { Applied } \\
\text { confining } \\
\text { pressure } \\
(\mathrm{MPa})\end{array}$ & $\begin{array}{l}\text { Simulated } \\
\text { bond strength } \\
(\mathrm{MPa})\end{array}$ & $\begin{array}{c}\text { Mean } \\
\text { experimental } \\
\text { bond strength } \\
(\mathrm{MPa})\end{array}$ & $\begin{array}{l}\text { Mean error } \\
(\%)\end{array}$ & $\begin{array}{l}\text { Simulated } \\
\text { bond strength } \\
(\mathrm{MPa})\end{array}$ & $\begin{array}{c}\text { Mean } \\
\text { experimental } \\
\text { bond strength } \\
(\mathrm{MPa})\end{array}$ & $\begin{array}{c}\text { Mean error } \\
(\%)\end{array}$ \\
\hline 0 & 13.26 & 13.32 & 0.4 & 11.43 & 11.73 & 2.6 \\
\hline 9 & 14.05 & 13.53 & 3.7 & 13.57 & 14.16 & 4.3 \\
\hline 14 & 14.38 & 14.51 & 0.9 & 14.24 & 13.51 & 5.1 \\
\hline \multirow[t]{2}{*}{20} & 14.68 & 14.4 & 1.9 & 14.9 & 14.67 & 1.5 \\
\hline & \multicolumn{3}{|c|}{$\mathrm{d}_{\mathrm{s}}=22 \mathrm{~mm}$} & & & \\
\hline $\begin{array}{l}\text { Applied } \\
\text { confining } \\
\text { pressure } \\
(\mathrm{MPa})\end{array}$ & $\begin{array}{c}\text { Simulated } \\
\text { bond strength } \\
(\mathrm{MPa})\end{array}$ & $\begin{array}{c}\text { Mean } \\
\text { experimental } \\
\text { bond strength } \\
(\mathrm{MPa})\end{array}$ & $\begin{array}{c}\text { Mean error } \\
(\%)\end{array}$ & & & \\
\hline 0 & 9.98 & 10 & 0.2 & & & \\
\hline 9 & 13.08 & 13.81 & 5.5 & & & \\
\hline 14 & 13.92 & 14.21 & 2.0 & & & \\
\hline 20 & 14.66 & 14.83 & 1.1 & & & \\
\hline
\end{tabular}

349 Table 5. Simulated and experimental bond strength and mean error. Pullout tests from [41].

350 The results are summarized in Table 3, Table 4 and Table 5 with a comparison on the mean values of 351 the simulated and experimental bond strength in each configuration. For a given configuration 352 (same reference, same steel diameter and same applied confinement pressure), the mean error is 353 also computed as the mean difference between the simulated bond strength and each measured 354 experimental bond strength, over the simulated bond strength.

355 A good agreement is generally obtained for the different values of the applied pressures and in the different geometrical and material configurations (especially for different $\left(\frac{c}{d_{s}}\right)$ ). It is to be noted that 
Figure 19. Concrete mesh for the reinforced concrete tie.

\subsection{Presentation of the test} respectively (Figure 19).

the experimental results may show an expected certain dispersion. In this case, the validation of the simulation is obtained if the simulation results (which are by definition deterministic in our case) are in the range of the experimental ones (with a maximum mean error equal to $15 \%$, which is quite reasonable here). As a conclusion, the proposed comparison validates the proposed methodology and especially the evolution law for the bond stress (at least regarding the bond strength).

\section{Structural consequences of the confinement effect - structural case}

The previous section was dedicated to the validation of the bond stress - slip law as a function of the lateral pressure along the steel bar. In this section, the consequences at the structural level is going to be investigated by the simulation of a reinforced concrete tie loaded both in tension and in confinement. The consequences are studied in terms of global and local behaviors.

A reinforced concrete tie (length $L$ equal to $1.15 \mathrm{~m}$, square section $S c$ equal to $0.01 \mathrm{~m}^{2}$ ), crossed by a steel bar (diameter $d_{s}$ equal to $10 \mathrm{~mm}$ for a section $S_{s}$ equal to $78.5 \mathrm{~mm}^{2}$ ) is considered (Figure 18). Concrete and steel are meshed using solid elements for concrete and truss elements for steel,

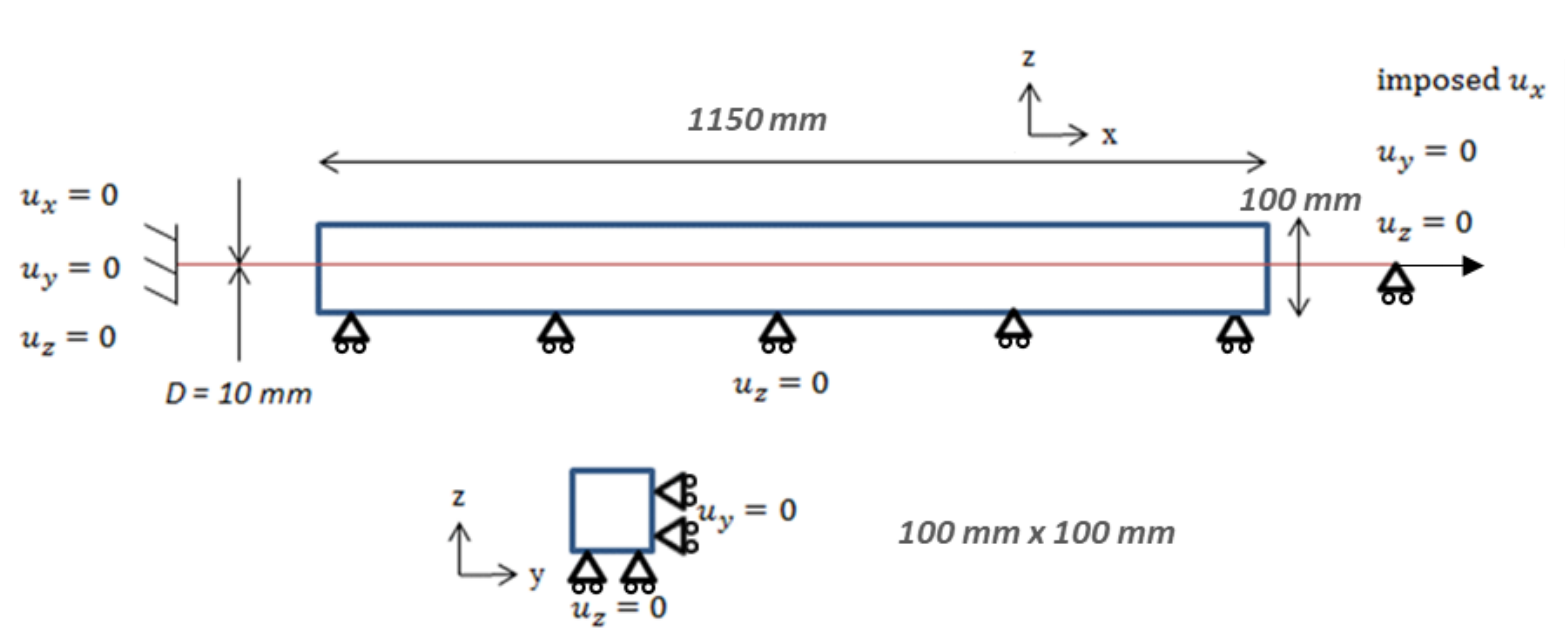

Figure 18. Presentation of the reinforced concrete tie. Geometry, boundary conditions and loading.

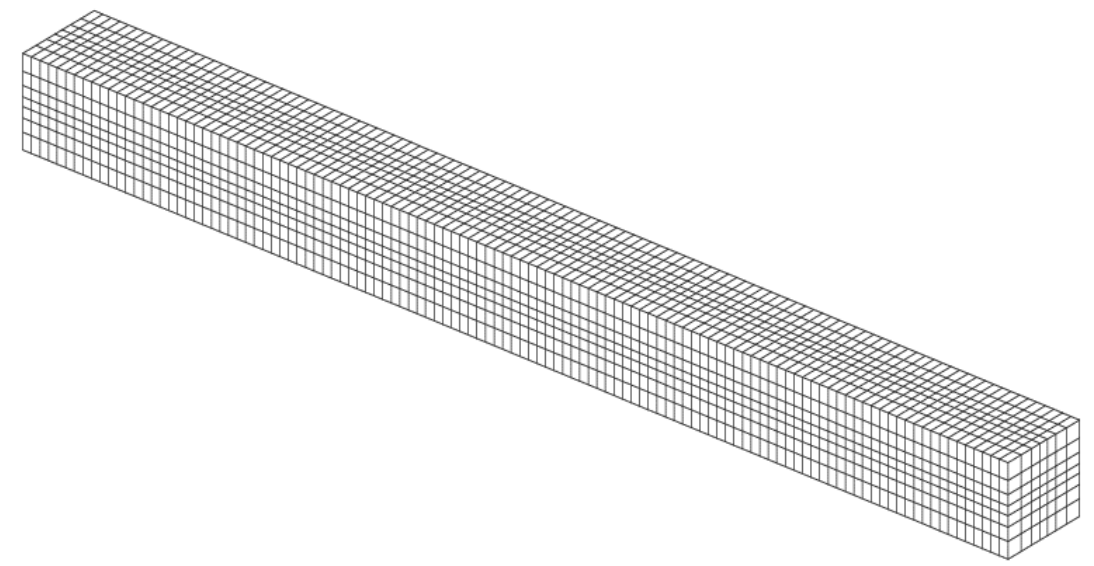


Table 6. Steel parameters.

\begin{tabular}{|c|c|c|c|c|}
\hline Young modulus & Poisson ratio & Tensile strength & $\begin{array}{c}\text { Compressive } \\
\text { strength }\end{array}$ & Fracture energy \\
\hline$E_{c}$ & $v_{c}$ & $f_{t}$ & $f_{c}$ & $G_{f}$ \\
\hline $30.2 \mathrm{GPa}$ & 0.2 & $2.9 \mathrm{MPa}$ & $56.9 \mathrm{MPa}$ & $150 \mathrm{~N} / \mathrm{m}$ \\
\hline
\end{tabular}

At each end of the steel bar, one element is added to apply the boundary conditions (no displacement at one end) and the loading (imposed horizontal displacement at the other end) (Figure 18). This particular structural test was chosen because it was successfully modeled in [24] and experimentally studied in [49].

The steel bar is modeled using an elastic-plastic law with linear hardening. Concrete follows the damage constitutive law presented in the previous section from [47]. Parameters given in Table 6 and Table 7 are chosen, in agreement with the experimental data. A random distribution of the tensile strength is introduced in order to localize the damage during loading (Figure 20). This Gaussian, stationary random scalar field is generated using the turning band method. It has an isotropic exponential covariance, whose matrix is computed from the standard deviation and the correlation lengths. The mean value, the standard deviation and the correlation length are chosen equal to the mean tensile strength $(2.9 \mathrm{MPa}), 5 \%$ and $3 \mathrm{~cm}$ respectively.

For the bond model, only the bond stress - slip law $\tau_{0}\left(\delta_{t}\right)$ has to be provided. A piecewise linear curve is chosen, following the recommendations from [11]. The parameters are given in Table 8. The effect of the confinement is taken into account using the methodology presented in the previous sections (calculation of $\alpha$ especially).

A monotonic increasing displacement is applied to the loaded end of the steel bar. To evaluate the influence of the active confinement, a compressive pressure $\left(\mathrm{P}_{\text {conf }}\right)$ can be applied, through a surface pressure, on both lateral faces (normal to the direction of the steel bar) before the loading in displacement. The pressure is then kept constant during the imposed displacement. The lateral pressures are chosen to be equal to 5, 10 or $20 \mathrm{MPa}$.

\begin{tabular}{|c|c|c|c|}
\hline Young modulus & Poisson ratio & Yielding stress & Hardening modulus \\
\hline $\mathrm{E}_{\mathrm{s}}$ & $v_{\mathrm{s}}$ & $\sigma_{s}^{e}$ & $\mathrm{E}_{\mathrm{h}}$ \\
\hline $200 \mathrm{GPa}$ & 0.3 & $500 \mathrm{MPa}$ & $3245 \mathrm{MPa}$ \\
\hline
\end{tabular}

Table 7. Concrete parameters.

\begin{tabular}{|c|c|c|c|c|c|c|}
\hline Bond stress (MPa) & 2 & 10 & 13.2 & 21 & 2 & 2 \\
\hline Slip (mm) & 0.002 & 0.1 & 0.25 & 0.765 & 1.5 & 1.8 \\
\hline
\end{tabular}




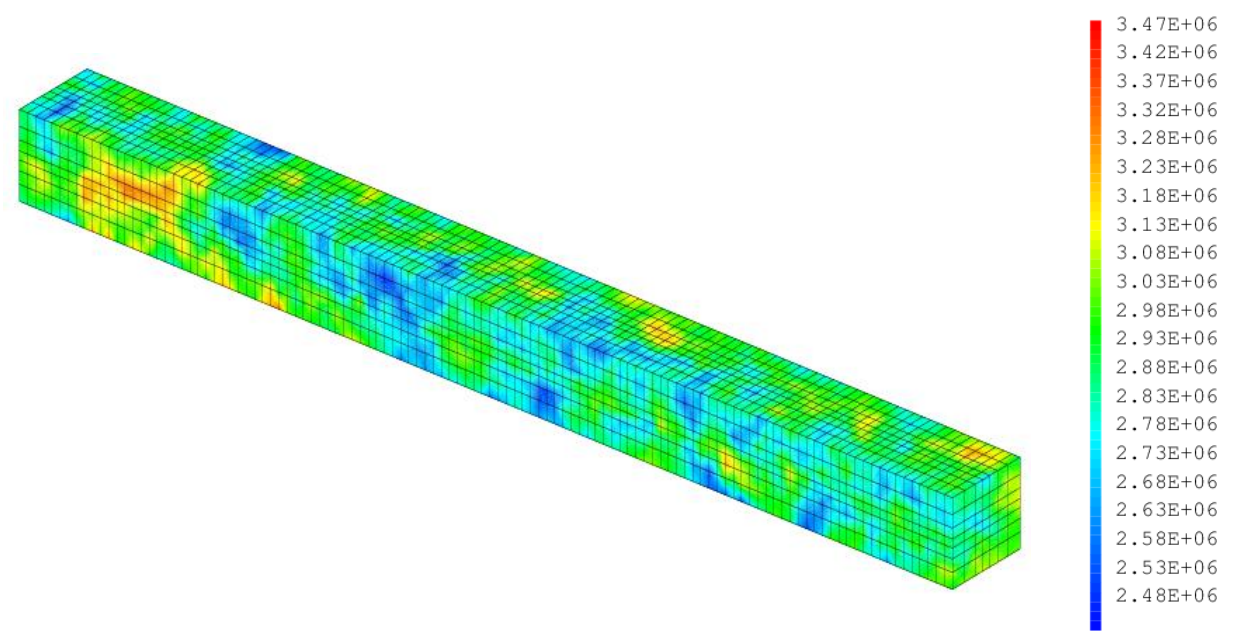

Figure 20. Distribution of the initial tensile strength (in Pa) in the reinforced concrete tie.

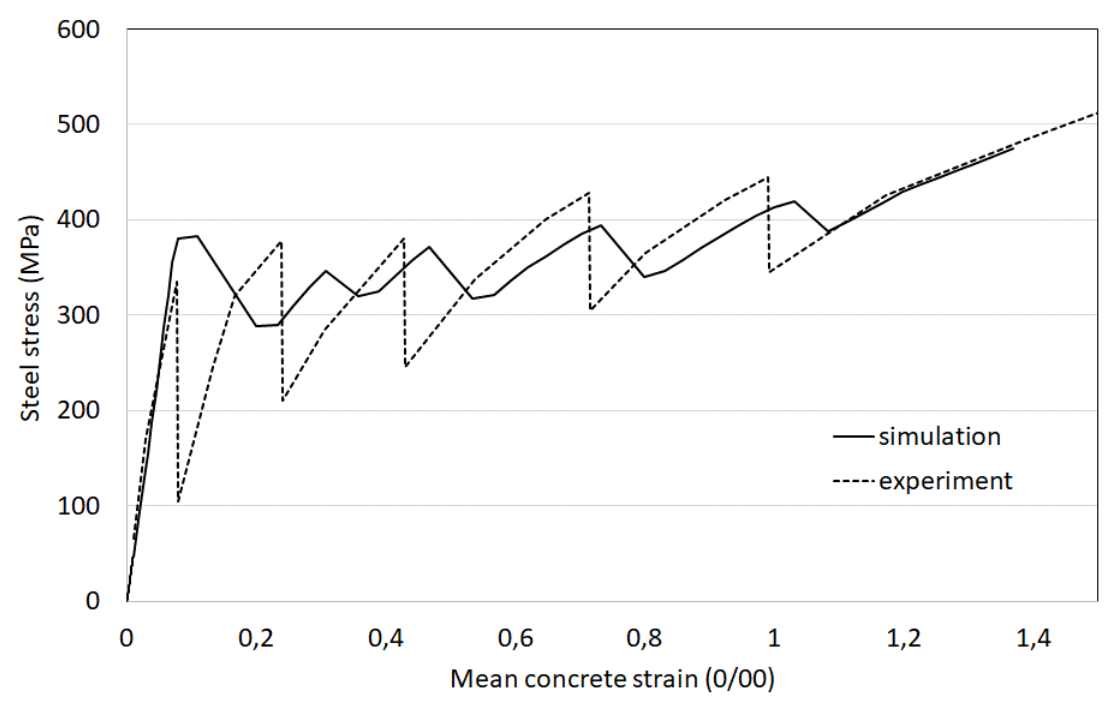

Figure 21. Steel stress as a function of the mean concrete strain. Comparison between the experimental result and the simulation at $\mathrm{P}_{\text {conf }}=0 \mathrm{MPa}$.

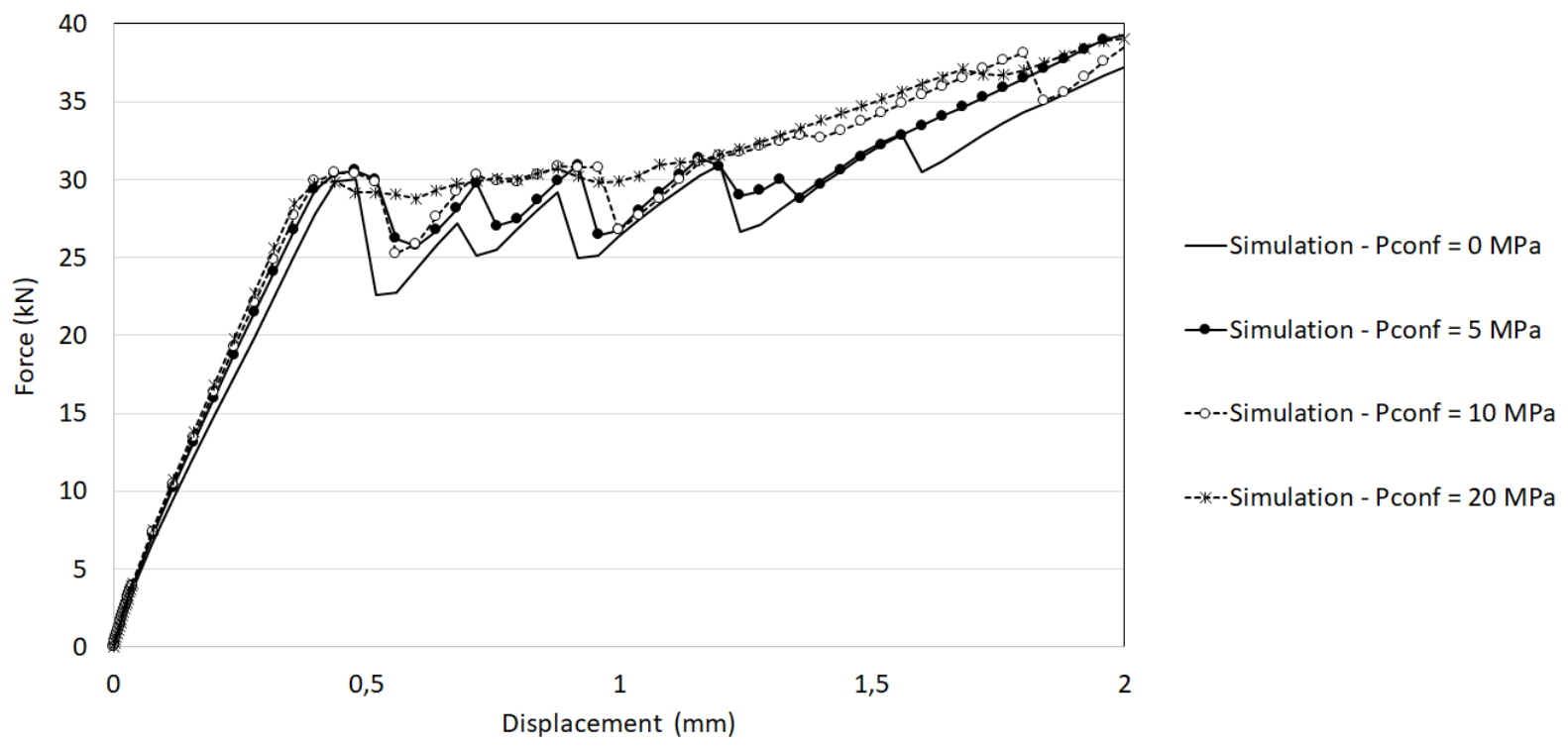

Figure 22. Force - displacement curves for the reinforced concrete tie considering different applied confinement pressures. 
Numerical results are compared in terms of global force - displacement curves and local evolutions (mechanical degradation especially). The experimental comparison for $\mathrm{P}_{\text {conf }}=0 \mathrm{MPa}$ is first provided. Figure 21 gives the evolution of the steel stress at the end of the bar as a function of the mean strain in concrete, as considered in [49]. A good agreement is obtained, which validates the methodology for the simulation. The expected differences between the simulation and the experimental curve have already been discussed in [24].

Figure 22 shows the evolution of the force as a function of the applied displacement for different external pressures. In every case, the expected global evolution is obtained in three main steps: a linear regime in which concrete and steel behave elastically, then a nonlinear regime where concrete is gradually damaged (active cracking) and finally a stage where the number of cracks in concrete does not evolve any more (stabilized cracks). Some unloading zones are also observed when new localized damaged zones appear. The effect of the confinement pressure is especially observed on these local unloading phases, which are less significant when the confinement pressure is high.

Moreover, the first loading stage of the force-displacement curve is found to be stiffer as the confinement pressure increases, a phenomenon that was expected as the confinement pressure tends to stiffen the bond stress - slip law (Eq. (8)). It is also to be noted that the force $F_{n l}$ which corresponds to the first unloading (at about $31 \mathrm{kN}$ ) is almost the same whatever the confining pressure. It can be demonstrated ([1]), if the length of the tie is enough compared to the transfer length (which is the case here, see Figure 26), that $F_{n l}$ can be estimated through the following equation:

$F_{n l}=\frac{f_{t} \cdot\left(E_{s} S_{s}+E_{c} S_{c}\right)}{E_{c}}$

This equation is not dependent on the bond properties, as it is observed numerically.

The damage distributions in concrete at the last displacement increment are provided in Figure 23 (entire concrete tie and cross section at the position of the steel bar). As mentioned in [24], for a zero applied confinement pressure, localized damages zones appear along the tie. The higher the confinement pressure, the higher the number of localized damaged zones. For high values of the confinement pressure (20 MPa), as the bond is stronger, damage is also observed along the steel bar, almost continuously. The confining pressure also affects the value of the damage at the exit point of the rebar with a decreasing value of the mechanical degradation with an increasing confinement. The constitutive model for concrete may explain this effect, with an increasing resistance to local shear with increasing compressive stresses.

Figure 24 illustrates the distribution of the stress along the steel bar at the end of the loading. Peaks in the stress are related to the position of the cracks, which can also be located from the change in the sign of the slip as illustrated in Figure 25 [35]. It enables to characterize, even using a damage model, both the position and the opening of "equivalent cracks" using an additional post-processing step on the relative displacement [35]. From these results, it is shown that the increase in the confinement pressure is responsible for an increase in the number of cracks. For $P_{\text {conf }}=20 \mathrm{MPa}$, the distribution of the stress along the rebar (between $x=0.6$ and $x=0.8 \mathrm{~m}$ ) is disrupted by the continuous damage localization. 
From the slip distribution, the number of cracks and average crack spacing are finally computed and summarized in Table 9. As expected from the steel stress distribution, the higher the confinement, the higher the number of cracks. This is essentially due to the stiffening of the bond with the increase in the confinement pressure, which decreases the transfer length and enables the apparition of closer "cracks" (decrease in crack spacing).

454
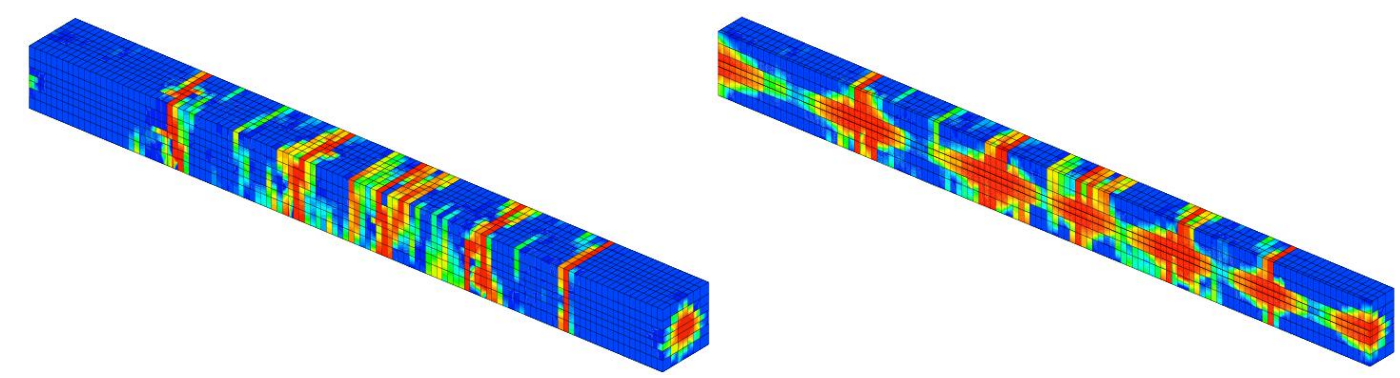

$$
\mathrm{P}_{\text {conf }}=0 \mathrm{MPa}
$$
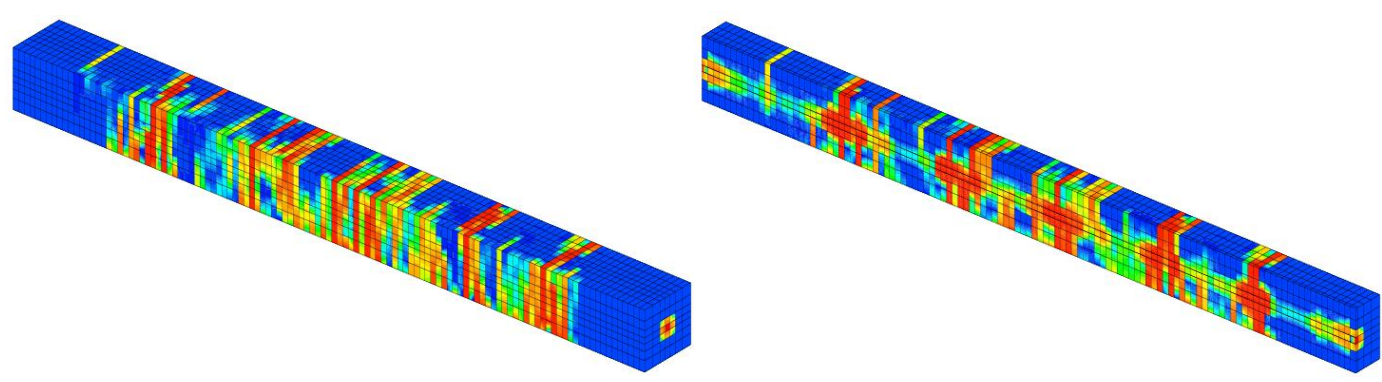

$$
\mathrm{P}_{\text {conf }}=5 \mathrm{MPa}
$$
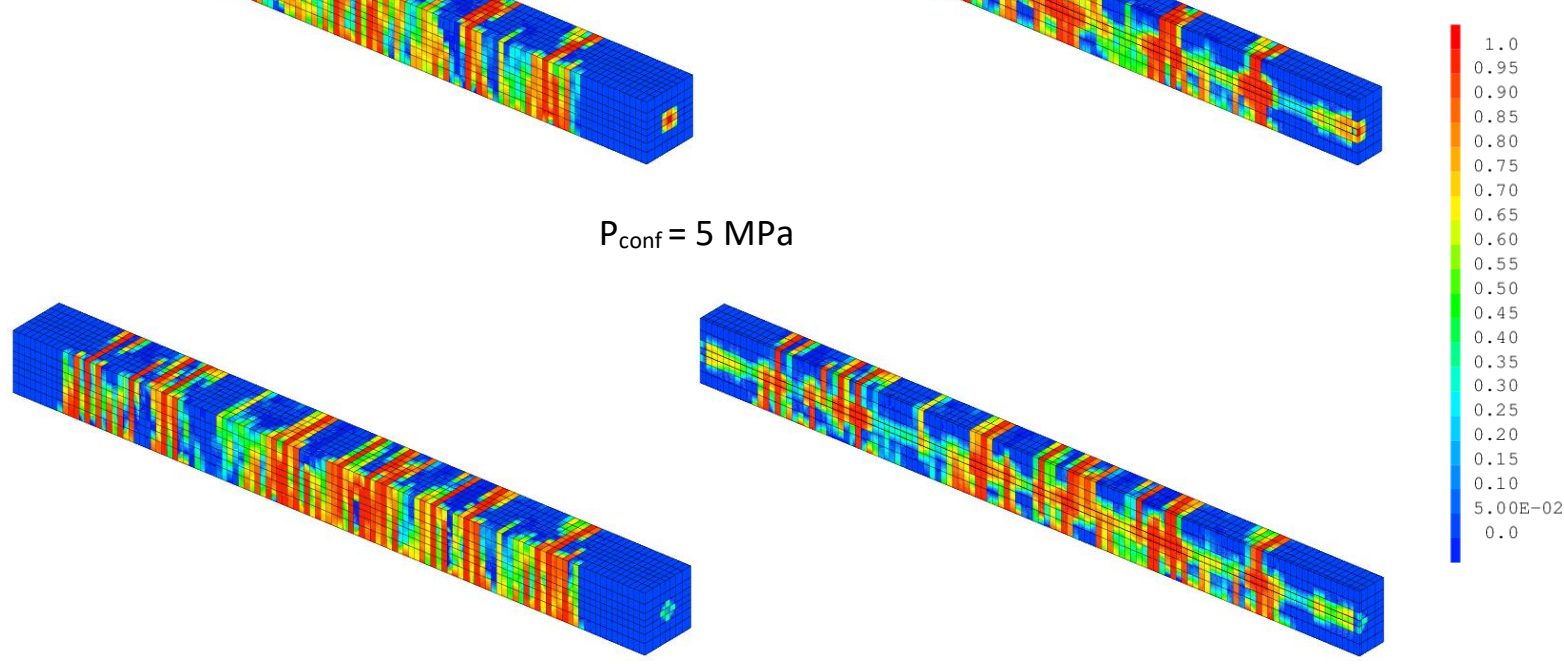

$$
\mathrm{P}_{\text {conf }}=10 \mathrm{MPa}
$$

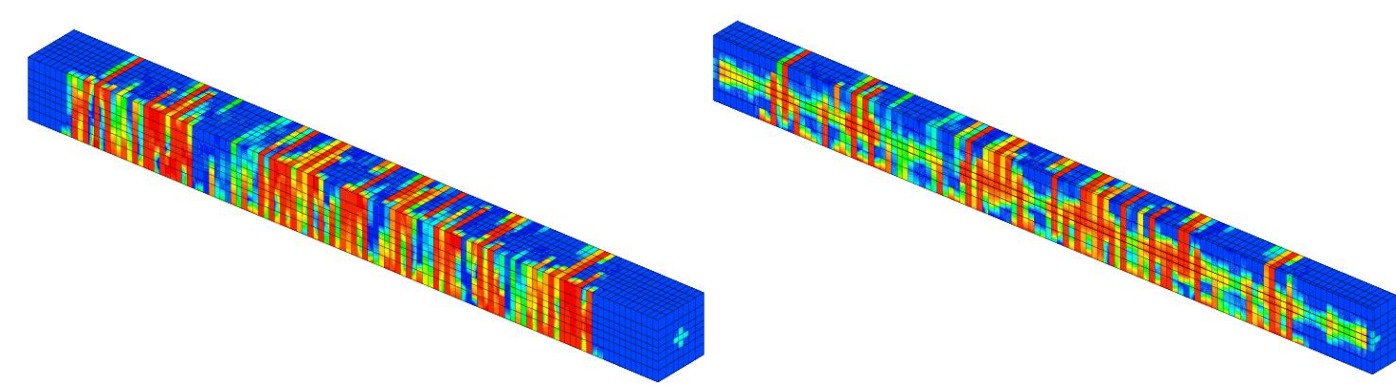

$$
\mathrm{P}_{\text {conf }}=20 \mathrm{MPa}
$$

Figure 23. Damage distributions at the end of the loading for different applied confinement pressures. 




Figure 24. Evolution of the stress along the steel bar for different confinement pressures - Last displacement 457 increment.

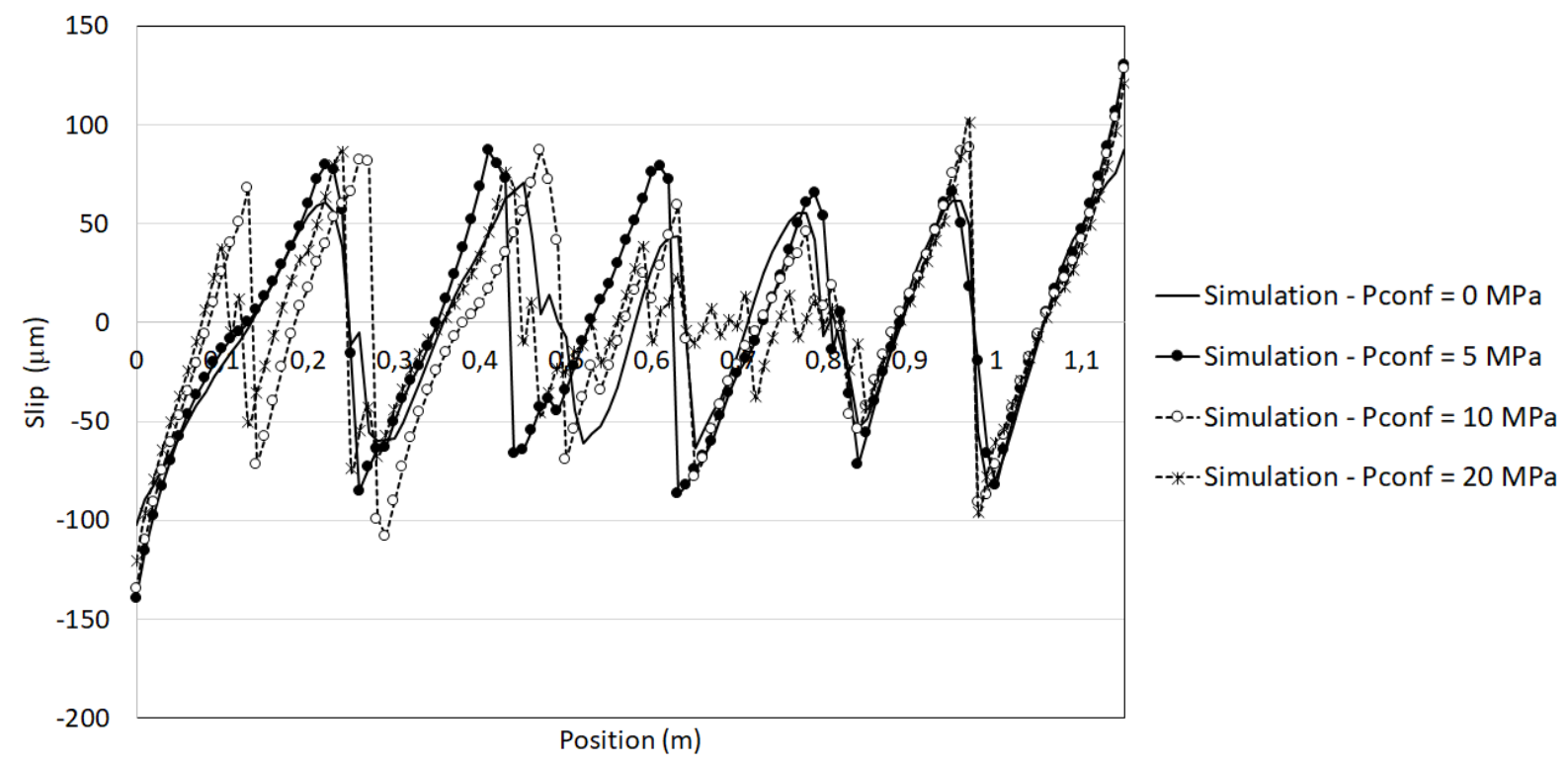

Figure 25. Evolution of the slip along the steel bar for different confinement pressures. Last displacement increment.

\begin{tabular}{|c|c|c|c|c|}
\cline { 2 - 5 } \multicolumn{1}{c|}{} & $\mathrm{P}_{\text {conf }}=0 \mathrm{MPa}$ & $\mathrm{P}_{\text {conf }}=5 \mathrm{MPa}$ & $\mathrm{P}_{\text {conf }}=10 \mathrm{MPa}$ & $\mathrm{P}_{\text {conf }}=20 \mathrm{MPa}$ \\
\hline Number of cracks & 5 & 5 & 6 & $\sim 6^{*}$ \\
\hline Average spacing (mm) & 183 & 182 & 168 & 170 \\
\hline Minimum spacing (mm) & 150 & 160 & 140 & 250 \\
\hline Maximum spacing(mm) & 240 & 190 & 240 & 100 \\
\hline
\end{tabular}




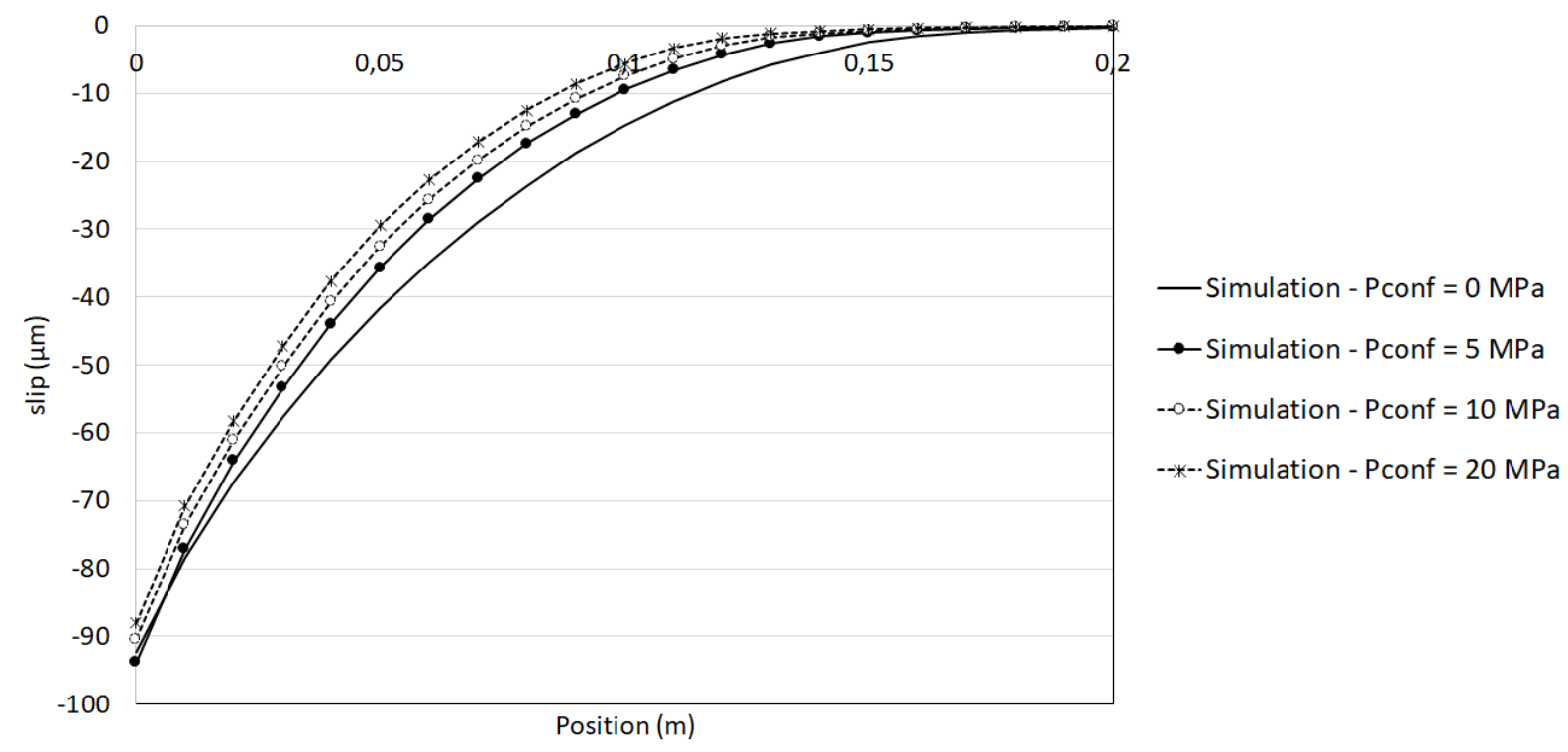

Figure 26. Evolution of the slip along the steel bar in the elastic phase for different confinement pressures.

\begin{tabular}{|c|c|c|c|c|}
\hline Confinement pressure (MPa) & 0 & 5 & 10 & 20 \\
\hline Transfer length (cm) & 14.1 & 12.8 & 11.5 & 10.7 \\
\hline
\end{tabular}

Table 10. Computed transfer length.

This effect is also underlined in Figure 26, which provides the evolution of the slip along the rebar during the elastic regime. From this evolution, it is possible to evaluate the corresponding transfer lengths, considering that the transfer length is the length to reach a $5 \mu \mathrm{m}$ slip from the end of the bar. The computed values are summarized in Table 10, which confirms the decrease in the transfer length with an increasing confinement pressure.

\section{Conclusions}

In this contribution, a numerical model to consider the effect of the stress state on the bond behavior between steel and concrete was proposed. It is based on a zero thickness element, adapted to large-scale simulations and the use of 1D elements for steel bars. It supposes the definition of a bond stress - slip law that includes the confining pressure around the steel bar as a parameter. The implementation of the model was presented and the calibration of the bond law was discussed. A general equation was especially proposed. Based on experimental observations from the state-ofthe-art, it includes a different behavior in confining tension or compression and two different phases depending on the concrete cover to steel diameter ratio.

The evolution law was validated through the comparison to 28 experimental pullout tests. The model was able to reproduce the evolution of the bond stress (especially the bond strength) as a function of the applied confinement pressure, whatever the configuration. A methodology was proposed, especially to take into account the non-zero lateral pressure, even in the case of a zero applied confinement pressure (structural effect due to pullout configuration). Considering the full range of simulated pullouts, the maximum mean error between the simulated and experimental bond strength reaches $15 \%$, which is reasonable regarding the wide variability in the experimental results.

Finally, the consequences at the structural level were investigated on a reinforced concrete tie. The response for different levels of confining pressures was studied. It shows the capability of the model 
to reproduce the "expected" tendencies with especially an increase of the initial elastic stiffness with increasing pressures and consequently a higher number of cracks in the stabilized nonlinear regime. The "transfer length" was also shown to decrease with increasing confining pressures.

As a conclusion, the proposed model is able to simulate the mechanical behavior of reinforced concrete at the structural scale, including the confinement effect. However, additional experimental validations are necessary to further evaluate the correctness and the validity of the proposed slip model. It would suppose the proposition of adapted experimental campaigns to focus on the confinement effect. The applicability of the model to more full-scale applications (including for example the applications studied in [50], [51]) could then be demonstrated.

\section{Acknowledgments}

The authors gratefully acknowledge the partial financial support from ENGIE for the development and the analysis of the simulation results.

\section{References}

[1] Casanova A., Jason L., Davenne L., Bond slip model for the simulation of reinforced concrete structures, Engineering Structures, 39, pp.66-78, 2012

[2] Eurocode 2. Design of concrete structures, EN 1992, 2007

[3] Jason L., Masson B., Comparison between continuous and localized methods to evaluate the flow rate through containment concrete structures, Nuclear Engineering and Design, 277, pp. 146153, 2014

[4] Lutz L.A., Gergely P., Mechanics of bond and slip of deformed bars in concrete, ACl Journal, 64, pp.711-721, 1967

[5] Eligehausen R., Popov E., Bertero V.V., Local bond stress-slip relationships of deformed bars under generalized excitations, University of California, Report $n^{\circ}$ UCB/EERC-83/23, 1983

[6] Zuo J., Darwin D., Bond slip of high relative rib area under cyclic loadings, ACl Structural Journal, 97, pp.331-335, 2000

[7] Bouazaoui L., Li A., Analysis of steel/concrete interfacial shear stress by means of pull out tests, Material Research, 11, pp.453-457, 2008

[8] Daoud A., Lorrain M., Elgonnouni M., Résistance à l'arrachement d'armatures ancrées dans le béton autoplaçant, Materials and Structures, 35, pp.395-401, 2002

[9] Tepfers R., Cracking of concrete cover along anchored deformed reinforcing bars, Magazine of concrete research, 31, 106, pp.3-12, 1979

[10] Desnerck P., de Schutter G., Taerwe L., A local bond stress-slip model for reinforcing bars in selfcompacted concrete, Proceedings of Framcos-7 conference, 2010

[11] Torre-Casanova A., Jason L., Davenne L., Pinelli X., Confinement effects on the steel-concrete bond strength and pull-out failure, Engineering Fracture Mechanics, 97, pp. 92-104, 2013

[12] Yong Y. K., Nour M. G. and Nawy E. G. Behavior of Laterally Confined High-Strength Concrete under Axial Loads, Engineering Structures, 114, 2, pp. 332-351, 1988 
[13] Xu F., Wu Z., Zheng J., Yu H., Li Q., Experimental study on the bond behavior of reinforcing bars in concrete subjected to lateral pressure, Journal of Materials in Civil Engineering, 24, 1, pp.125-133, 2012

[14] Zhang X., Wu Z., Wei Z., Zheng J., Dong W., Bouchair A., Ultimate bond strength of plain round bars embedded in concrete subjected to uniform lateral tension, Construction and Building Materials, 117, pp.163-170, 2016

[15] Malvar R.J., Bond of reinforcement under controlled confinement, $\mathrm{ACl}$ Materials, 89, 6, pp.593-601, 1992

[16] Verderame G., Ricci P., DeCarlo G., Manfredi G., Cyclic bond behavior of plain bars. I: Experimental investigation, Construction Building Materials, 23, 12, pp.3499-3511, 2009

[17] Jin L., Li D., Du X., Mechanical behavior and size effect of moderate high-strength RC columns under monotonic and cyclic axial compression, Engineering Structures, 124, pp.269-285, 2016

[18] Gambarova P. G., Rosati G.P., Zasso B., Steel-to-concrete bond after concrete splitting: Test Results, Materials and Structures, 22, pp.35-47, 1989

[19] Lowes L. N., Moehle J. P., Govindjee S., Concrete-steel bond model for use in finite element modeling of reinforced concrete structures, ACI Structural Journal, pp. 501-511, 2004

[20] Xu F., Wu Z., Zheng J., Hu Y., Li Q., Bond behavior of plain round bars in concrete under lateral pressures, ACl Structural Journal, 111, 2014

[21] Zhang X., Dong W., Zheng J., Wu Z., Hu Y., Li Q., Bond behavior of plain round bars embedded in concrete subjected to lateral tension, Construction and Building Materials, 54, pp.17-26, 2014

[22] Wu Z., Zhang X., Zheng J., Hu Y., Bond Behavior of plain round bars embedded in concrete subjected to biaxial lateral tensile-compressive stresses, Journal of Structural Engineering, 140, 4, 2014

[23] Lindorf A., Lemnitzer L. and Curbach M., Experimental investigations on bond behavior of reinforced concrete under transverse tension and repeated loading, Engineering Structures, 31, 7, pp.1469-1476, 2009

[24] Mang C., Jason L., Davenne L., A new bond slip model for reinforced concrete structures: Validation by modelling a reinforced concrete tie, Engineering Computations, 32, 7, pp.19341958, 2015

[25] Jason L., Torre-Casanova A., Davenne L., Pinelli X., Cracking behavior of reinforced concrete beams. Experiment and simulations on the numerical influence of the steel concrete bond, International Journal of Fracture, 180, 2, pp.243-250, 2013

[26] Gupta A.K., Maestrini R., Tension-stiffness model for reinforced concrete bars, Journal of Structural Engineering, 116, 3, pp.769-790, 1990

[27] Balazs G.L., Cracking analysis based on slip and bond stresses, ACI Materials Journal, pp.340-348, 1993

[28] Barros J.A.O., Taheri M., Salehian H., A model to simulate the moment-rotation and crack width of FRC members reinforced with longitudinal bars, Engineering Structures, 100, pp.43-56, 2015 
[29] Ngo D., Scordelis A.C., Finite Element Analysis of Reinforced Concrete Beams, ACl Journal, 64, pp.152-163, 1967.

[30] Dominguez N., Brancherie D., Davenne L.,Ibrahimbegovic I., Prediction of crack pattern distribution in reinforced concrete by coupling a strong discontinuity model of concrete cracking and a bond-slip of reinforcement model, International Journal for Computer-Aided Engineering and Software, 22, pp.558-582, 2005

[31] Richard R., Ragueneau F., C. Cremona, Adélaide L. , Tailhan J.L., A Three-dimensional steel/concrete interface model including corrosion effects, Engineering Fracture mechanics, 77, pp.951-973, 2010

571 [32] Monti G., Filippou F.C., Spacone E., Analysis of Hysteretic Behavior of Anchored Reinforcing Bars, 572 ACl Structural Journal, 94, pp.248-261, 1997

[33] Ibrahimbegovic A., Boulkertous A., Davenne L., Brancherie D., Modeling of reinforced-concrete structures providing crack spacing based on XFEM, ED-FEM and novel operator split solution procedure, International Journal for Numerical Methods in Engineering, 83, 4, pp.452-481, 2010

[34] Markou, G., Mourlas, C., Garcia, R., Pilakoutas, K. and Papadrakakis, M., Cyclic Nonlinear Modeling of Severely Damaged and Retrofitted Reinforced Concrete Structures, COMPDYN 2019, 7th International Conference on Computational Methods in Structural Dynamics and Earthquake Engineering, 24-26 June 2019, Crete, Greece

[35] Mang C., Jason L., Davenne L., Crack opening estimate in reinforced concrete walls using a steel-concrete bond model, Archives of civil and mechanical engineering, 16, pp.422-436, 2016

[36] Lykidis G., Static and dynamic analysis of reinforced concrete structures with 3D finite elements and the smeared crack approach, PhD thesis, NTUA, Greece, 2007

[37] Markou, G., Genco, F., Seismic Assessment of Small Modular Reactors: NuScale Case Study for the 8.8 Mw Earthquake in Chile, Nuclear Engineering and Design, 342, pp.176-204, 2019

[38] Markou, G., Papadrakakis, M., An Efficient Generations Method of Embedded Reinforcement in Hexahedral Elements for Reinforced Concrete Simulations, Advances in Engineering Software, 45, 1, pp.175-187, 2012

[39] Robins P. J., Standish I. G., The effect of lateral pressure on the bond of round reinforcing bars in concrete, Internal Journal of Adhesion and Adhesives, 2, 2, pp.129-133, 1982.

[40] Orangun C. O., Jirsa J. O., Breen J. E., The Strength of Anchored Bars: Re-evaluation of test data on development length and splices, ACI Structural Journal, 74, 3, pp.114-122, 1977 coarse aggregate concrete under lateral compression load, Construction and Building Materials, 150, pp. 529-537, 2017

596 [42] ACl 318-14, Building Code Requirements for Structural Concrete (ACl 318-14), American 597 Concrete Institute, 2014

598 [43] RILEM. Essai portant sur l'adhérence des armatures de béton - Essai par traction, Matériaux et 599 Constructions, Vol 3, N¹5, p. 175-178, 1970.

600 [44] Untrauer R.E., Henry R.L., Influence of Normal Pressure on Bond Strength, ACI Journal, pp.577601585,1965 
602 [45] Lowes L.N., Finite Element Modeling of Reinforced Concrete Beam-Column Bridge Connections, 603 PhD thesis, University of California, Berkeley

604 [46] Cast3M, http://www-cast3m.cea.fr, 2019

605 [47] Costa C., Pegon P., Arêde A., Castro J.. Implementation of the damage model in tension and 606 compression with plasticity in Cast3M ; JRC Report ; 2004.

607 [48] Hillerborg A., Modeer M., Peterson P.E., Analysis of Crack Formation and Crack Growth in 608 Concrete by means of Fracture Mechanics and Finite Elements. Cement and concrete Research, 6, 609 pp.773-782, 1976

610 [49] Farra, B., Influence de la résistance du béton et de son adhérence avec l'armature sur la 611 fissuration, PhD Thesis, Ecole Polytechnique Fédérale de Lausanne, 1995

612 [50] Engen, M., Hendriks, M. A. N., Øverli, J. A., Åldstedt, E., Non-linear finite element analyses 613 applicable for the design of large reinforced concrete structures, European Journal of Environmental 614 and Civil Engineering, pp.1-23, 2017

615 [51] Markou, G., Computational performance of an embedded reinforcement mesh generation 616 method for large-scale RC simulations, International Journal of Computational Methods, 12, 3, 2015 